\title{
A study of changes in apparent ionospheric reflection height within individual lightning flashes
}

Vijaya B. Somu, ${ }^{1}$ Vladimir A. Rakov, ${ }^{1}$ Michael A. Haddad, ${ }^{1,2}$ and

Steven A. Cummer ${ }^{3}$

Corresponding author: Vladimir A. Rakov (rakov@ece.ufl.edu)

${ }^{1}$ Department of Electrical and Computer

Engineering, University of Florida,

Gainesville, Florida, USA

${ }^{2}$ Now at Department of Electrical

Engineering, University of California, Los

Angeles, California, USA

${ }^{3}$ Department of Electrical and Computer

Engineering, Duke University, Durham,

North Carolina, USA

(C) 2015. This manuscript version is made available under the Elsevier user license

http://www.elsevier.com/open-access/userlicense/1.0/ 
Abstract. Ionospheric reflection heights estimated using the zero-to-zero and peak-to-peak methods to measure skywave delay relative to the ground wave were compared for 108 first and 124 subsequent strokes at distances greater than $100 \mathrm{~km}$. For either metric there was a considerable decrease in average reflection height for subsequent strokes relative to first strokes. We showed that the observed difference cannot be explained by the difference in frequency content of first and subsequent return-stroke currents. Apparent changes in reflection height (estimated using the peak-to-peak method) within individual flashes for 54 daytime and 11 nighttime events at distances ranging from $50 \mathrm{~km}$ to $330 \mathrm{~km}$ were compared, and significant differences were found. For daytime conditions, the majority of the flashes showed either decrease (57\%) or non-monotonic variation (39\%) in reflection height with respect to the immediately preceding stroke. With respect to the first stroke, $91 \%$ of the flashes showed monotonic decrease in height. For nighttime flashes, patterns in reflection height changes with respect to the immediately preceding stroke were as follows: $46 \%$ no change, $27 \%$ monotonic decrease, and $27 \%$ non-monotonic variation. When changes were measured with respect to the first stroke, 54\% of nighttime flashes showed monotonic decrease and $46 \%$ no change. Ionospheric reflection height tends to increase with return-stroke peak current. The observed daytime effects can be explained by (a) the dependence of EMP penetration depth on source intensity, which decreases with stroke order, (b) additional ionization associated with elves, or (c) combination of (a) and (b) above. 


\section{Introduction and literature review}

The ionosphere is a weak plasma (less than $1 \%$ of the neutral atoms are ionized) that has a complex structure composed of three major regions or layers, the $\mathrm{D}, \mathrm{E}$, and $\mathrm{F}$ regions. The lowest layer, the D region, extends in height from about 40 to $90 \mathrm{~km}$. Its typical electron density is of the order of $10^{9} \mathrm{~m}^{-3}$ in the daytime and diminishes to a much lower value after sunset. The E region of the ionosphere extends between about 90 and $160 \mathrm{~km}$. The electron density in this region typically has a value above $10^{11} \mathrm{~m}^{-3}$ in the daytime. At night, the electron density in the $\mathrm{E}$ region is about two orders of magnitude lower. Above the E region is the F region which extends to a height of $1000 \mathrm{~km}$ or so. The peak F-region electron density has an average value of about $2 \times 10^{12} \mathrm{~m}^{-3}$ during the day and $2 \times 10^{11} \mathrm{~m}^{-3}$ at night. The ionospheric plasma appears to be opaque to electromagnetic waves of frequencies below the so-called plasma frequency $(9 \mathrm{MHz}$ for electron density of $10^{12} \mathrm{~m}^{-3}$ and $285 \mathrm{kHz}$ for electron density of $10^{9} \mathrm{~m}^{-3}$ ). An electromagnetic wave of frequency below the plasma frequency may be absorbed or reflected by the ionospheric plasma depending upon the electron collision frequency with neutral atoms. A high collision frequency results in absorption of the incident electromagnetic energy, while a low collision frequency allows the electrons to reradiate in phase producing what is in essence a reflection of the incident electromagnetic energy. The absorption of high-frequency radio waves propagating in the ionosphere takes place mostly in the D region, where the product of the electron number density and the collision frequency reaches a maximum [Pavlov, 2014]. Ionospheric reflection in the D-region occurs where the real and imaginary parts of the index of refraction squared are equal to each other. The theory of interaction of electromagnetic waves with ionospheric plasma is found in works of Ratcliff [1959], Stix [1962], Spitzer [1962], Ginzburg [1970], Yeh and Liu [1972], Budden [1988], and Rakov and Uman [2003, Ch. 13].

Tropospheric thunderstorms have been reported to disturb the lower ionosphere, at altitudes of 65-90 $\mathrm{km}$, by convective atmospheric gravity waves and by electric field changes produced by lightning discharges. Theoretical simulations suggest that, under nighttime conditions, lightning electric fields reduce electron density (via enhancing electron attachment to oxygen molecules) at altitudes $75-85 \mathrm{~km}$ and substantially increase electron density (due to ionization of nitrogen and oxygen) at $85-95 \mathrm{~km}$ [e.g., Taranenko et al., 1993]. The rate of the density change depends on the amplitude and duration of 
the lightning electromagnetic pulse (EMP), and on the preceding (ambient) electron density profile [Shao et al., 2013]. The opposite EMP effects above and below the 85-km level may cause a sharpening of the electron density profile near $85 \mathrm{~km}$. More recent work [e.g., Marshall et al., 2010] shows that the altitude ranges of the effects often overlap and events might show only attachment or only ionization effects depending on source parameters.

Shao et al. [2013], using lightning VLF/LF signals to probe the ionospheric D region, observed that electron density in the nighttime D region (at $75-80 \mathrm{~km}$ ) was reduced significantly above a small storm, and the extent of the reduction was closely related in time and space to the rate of lightning discharges, which seems to be in support of the EMP-enhanced electron attachment theory. No electron density increase at higher altitudes, predicted by the theory, was observed by them. Shao et al. [2014] noted that the static electric field/current effect may induce more electrons at the lower level of the nighttime D region and that the two competing processes may cause the D-region electron density distribution to become highly inhomogeneous in space and time.

In contrast to nighttime conditions, no substantial electron density changes in response to lightning electric fields are predicted during daytime, since most of the electromagnetic energy goes into the excitation of the molecular levels lower than those of ionization and dissociative attachment [Taranenko et al., 1993]. Haldoupis et al. [2013] argues that even a powerful EMP is very unlikely to generate ionization changes near the daytime lower VLF reflection heights (expected to be around 70 $\mathrm{km}$ ), mainly because the electron mean free path there is too small in order for the electrons to gain sufficient energy to trigger impact ionization electron production. They, however, do not exclude entirely the possibility of momentary electron density depletions due to attachment at heights as low as $70 \mathrm{~km}$ by extremely powerful EMPs during daytime. Further, even though lightning electromagnetic fields should be heavily attenuated in the presence of elevated daytime D region electrical conductivities, a powerful EMP can reach the uppermost D region and produce ionization by impact there.

Ionospheric ionization by lightning occurs both by changes to the electron density, via ionization and attachment, and by changes to the collision frequency, via heating (i.e., changes to the electron mobility). Marshall [2014] showed that the dominant effect of lightning EMP in the upper atmosphere over short (of the order of milliseconds) time scales is collisional heating. It is likely to cause an increase of reflection height, which appears to be not supported by our observations. 
According to Shao et al. [2013], ionospheric reflection of a VLF/LF signal cannot be considered a specular reflection off a definite height or layer in the lower ionosphere. Inside the ionosphere, an upward-propagating signal is gradually refracted and eventually bent backwards towards the Earth, acting as an apparent reflection. A higher-frequency signal is refracted more slowly than a lowerfrequency signal and penetrates higher into the ionosphere. Therefore, the reflection is highly dispersive. For this reason, all the ionospheric reflection heights should be viewed as apparent or effective.

\section{Objectives and structure of the paper}

Haddad et al. [2012] found that the mean ionospheric reflection height for negative subsequent strokes was significantly lower than for first ones. They computed the ionospheric reflection height, $h_{1}$, for the first skywave as [e.g., Laby et al., 1940]:

$$
h_{1}=R_{e}\left[\cos \left(\frac{r}{2 R_{e}}\right)-1\right]+\sqrt{\left\{R_{e}^{2}\left[\cos ^{2}\left(\frac{r}{2 R_{e}}\right)-1\right]+\left(\frac{c t_{1}+r}{2}\right)^{2}\right\}}
$$

where $R_{e}=6367 \mathrm{~km}$ is the mean radius of the Earth, $\mathrm{r}$ is the distance to the lightning channel (labeled $\mathrm{D}$ in the figures presenting data), $t_{l}$ is the difference in arrival times of the first skywave and the ground wave, and $\mathrm{c}$ is the speed of light in free space. The corresponding geometry is illustrated in Figure 1. We will use equation (1) in this paper as well.

All field records examined by Haddad et al. [2012], were acquired under daytime conditions (between 12 noon and 8 p.m., local time) in May and June in Florida. Here, in section 4.3, we will consider additional data acquired, in the same time period and in the same location, under nighttime conditions (between 8 p.m. and 6 a.m., local time) to see if Haddad et al.'s [2012] findings will hold. Examples of daytime and nighttime wideband electric field waveforms, recorded at the Lightning Observatory in Gainesville (LOG), Florida [Rakov et al., 2014], are shown in Figures 2a and b, respectively. In order to make this paper consistent with previous pertinent publications, we use the atmospheric electricity sign convention (a downward-directed electric field change vector is considered as positive).

VLF electric field waveforms computed using the finite difference time domain (FDTD) technique for daytime ionosphere $\left(h^{\prime}=73 \mathrm{~km}, \beta=0.40 \mathrm{~km}^{-1}\right.$, where $\mathrm{h}^{\prime}$ is often referred to as the effective reflection height and $\beta$ is the steepness of the exponential electron density profile) are shown in Figure 3. Note 
that the ground-wave signatures in Figure 3 are bipolar, as expected [e.g., Rakov and Uman, 2003] at distances $(>50 \mathrm{~km})$ considered in this paper and that the second positive half-cycle occurs closer to the ground wave as distance increases, as expected for a skywave. Note also in Figure 3 that at distances ranging from 100 to $400 \mathrm{~km}$ the skywaves have the same polarity as the ground wave. This is consistent with experimental data on nighttime ionopsheric reflections obtained within about $200 \mathrm{~km}$ [e.g., Smith et al. 1999, plate 3; Schonland et al. 1940; Jacobson et al. 2012, Figs. 10 and 11]. Also given in Figure 3 are the corresponding differences in arrival times of the first skywave and the ground wave, $\mathrm{t}_{1}$ (measured using the peak-to-peak and zero-to-zero methods; discussed later in this section), and the ionospheric reflection heights, $\mathrm{h}_{1}$, computed using equation (1). The time of flight in Figure 3 is the expected $t_{1}$ which corresponds to a curved earth propagation model and expected reflection height of $73 \mathrm{~km}$. Figure 3 is our primary basis for both identification of skywaves and measurements of $t_{1}$ for daytime conditions. For nighttime conditions, the identification and measurements are less ambiguous. Uncertainties in estimating the daytime reflection height due to errors in distance and in selecting the position of the often not well pronounced skywave peak are discussed in Appendix A.

It is worth noting that the period from about 6 p.m. to 8 p.m. (local time) probably corresponds to transition from daytime to nighttime ionosphere (the so called solar terminator), but the waveforms recorded during that time period look similar to those recorded between 12 noon and 6 p.m. Sunrise and sunset average times in Gainesville, Florida, in May are 6:47 a.m. and 8:06 p.m., respectively, and they are 6:29 a.m. and 8:25 p.m. in June [Astronomical Applications Department website, United States Naval Observatory]. At 8 p.m. the sun is still incident on higher altitudes for some time, roughly 40 minutes at $100-\mathrm{km}$ altitude, but this fact was neglected, because there are only a few events in the time interval between 8:00 and 9:00 p.m. in our data set (see Figure S1).

In some cases, skywaves were not identifiable, apparently due to overlapping with direct waves produced by other lightning processes, or unmeasurable due to their small magnitude. One example of a stroke occurring $178 \mu$ s after the preceding one and overlapping its skywave is shown in Figure 4. Such behavior was observed in four flashes in our data set.

Haddad et al. [2012] assumed that the time interval between the onset of ground wave and the second zero crossing, labeled zero-to-zero interval in Figure 5, roughly represents the difference in 
times of arrival of the ground wave and the first skywave. An alternative measure could be the time interval between the peaks of the ground wave and the first skywave; that is, the peak-to-peak, as opposed to zero-to-zero interval. We will check in section 4.1 if the conclusions of Haddad et al. [2012] are influenced by their use of the zero-to-zero measure of the difference in arrival times of the ground wave and the first skywave.

Besides their analysis of wideband electric field data acquired at the Lightning Observatory in Gainesville (LOG), Florida [Rakov et al., 2014], Haddad et al. [2012] also used Duke University VLF (100 $\mathrm{Hz}$ to $25 \mathrm{kHz}$ ) magnetic field data to show that the apparent lowering of ionospheric reflection height is observable in the waveforms from individual flashes and not just in a statistical comparison of first and subsequent strokes. Here, we will use our wideband (16 Hz to at least $10 \mathrm{MHz}$ ) electric field measurements at LOG to verify those results. Also, in section 4.2, using the FDTD method [Hu and Cummer, 2006], we will compute electric field waveforms for typical first and typical subsequent stroke currents and show that the first skywave delays for them are essentially the same.

In section 4.4, we will examine the occurrence of different patterns in reflection height changes within individual flashes, as well as (in section 4.5) changes in reflection height as a function of return stroke peak current and preceding interstroke interval. Further, we will examine, in section 4.6, correlation between the magnitudes of the first skywave and the corresponding ground wave.

In addition to cloud-to-ground lightning events, we will examine in section 4.7 wideband electric field signatures (recorded using the same instrumentation at LOG) of one pair of compact intracloud lightning discharges (CIDs), to see if the ionospheric reflection height for the second CID in the pair was influenced by the first one.

\section{Data}

Data examined in this paper were acquired on three days during May and June of 2009 at LOG. A detailed description of the instrumentation and methodology used is given by Haddad et al. [2012]. Record length was set to $500 \mathrm{~ms}$ with a 100-ms pretrigger, so that most flashes were recorded in their entirety. Distances from LOG to the lightning channels were determined using NLDN (U.S. National 
Lightning Detection Network) data.

For the analysis of reflection height change patterns within individual flashes, we considered only events that occurred at distances exceeding $50 \mathrm{~km}$ (a compromise that allowed us to minimize the influence of electrostatic and induction field components and maximize the sample size). The total number of multiple-stroke flashes in this analysis was 65 , of which 11 occurred between 8 p.m. and 6 a.m. (local time) and were treated as nighttime events. The remaining 54 flashes occurred between 12 noon and 8 p.m. (local time) and were assigned to the daytime category. The total number of located strokes with identifiable/measurable skywaves in the 65 flashes was 211 (65 first and 146 subsequent). The diurnal variation of all the recorded strokes in the 65 multiple-stroke flashes is shown in Figure S1 (see Supplementary Material). All strokes transported negative charge to ground. The overwhelming majority of strokes occurred between 4 p.m. and 8 p.m. (a similar trend is seen in the diurnal variation of recorded flashes, not shown here). This is not surprising since nighttime storms in Florida are rare (Holle et al. [2014]; compare his Figures 4 and 6).

Histogram of NLDN-reported peak currents for 108 first and 124 subsequent return strokes recorded at distances greater than $100 \mathrm{~km}$ are shown in Figure S2 (see Supplementary Material). It is worth noting that we employed a triggered field measuring system with relatively high threshold to minimize triggering on cloud discharge pulses. As a result, NLDN-reported peak currents are biased toward larger values. Indeed, the geometric mean peak currents for first and subsequent strokes in Figure S2 are 93 and $28 \mathrm{kA}$, respectively, about a factor of 3 higher than typical values for first strokes and a factor of 2 to 3 higher for subsequent ones [e.g., Rakov and Uman, 2003]. Thus, our results may be applicable only to significantly larger than average lightning events.

\section{Analysis and results}

\subsection{Different approaches to measurement of first skywave delay relative to the ground wave}

In this section, we compare the results based on zero-to-zero and peak-to-peak methods to measure the time intervals between the ground wave and the first skywave (see Figure 5). For direct comparison, we used the same sample (108 first and 124 subsequent strokes located by the NLDN at 
distances greater than $100 \mathrm{~km}$ ) as the one examined by Haddad et al. [2012]. The results for the peakto-peak method are shown in Figures 6 and 7, and for both methods in Table 1. The standard errors in mean values of $\mathrm{h}_{1}$ in all cases are less than $3 \%$ of the mean value, being lower for the peak-to-peak method. The results for the zero-to-zero method slightly differ from those found in Haddad et al. [2012] due to our correcting an error in their calculations.

As seen in Table 1, the difference in $h_{1}$ for first and subsequent strokes is not significantly influenced by the method to measure $t_{1}$. The difference in $h_{1}$ between first and subsequent strokes is 11 $\mathrm{km}$ for both the zero-to-zero method and for the peak-to-peak one. The values of $\mathrm{h}_{1}$ appear to be too large for the daytime ionosphere (as often quoted for VLF), which could be due to the following three reasons (see also section 5): (a) many of the events assigned to the daytime category actually correspond to the terminator conditions, (b) most of our lightning events are considerably larger than average, and (c) our method tends to yield larger differences in arrival times of the ground wave and the first sky wave relative to the simple time-of-flight predictions as seen for larger distances in Figure 3. Other reasons (for example, the dominance of the induction component of electric field at ionospheric altitudes; e.g., Yashunin et al. [2007]) are possible.

Clearly, neither of the two metrics can be considered accurate (primarily because the daytime reflection process is highly dispersive), but the effect can be probably considered real, if the difference in ionospheric reflection heights is not materially influenced by the manner in which the difference in arrival times was measured (see also Figure 3). Only the peak-to-peak method is used in the rest of the paper. The model-predicted peak-to-peak intervals in Figure 3 are in reasonably good agreement (better than the zero-to-zero intervals) with simple time-of-flight predictions for expected $h_{1}=h^{\prime}=73$ $\mathrm{km}$. The mismatches in terms of effective reflection height vary from $-3.2 \%$ to $10 \%$ for the peak-topeak method vs. $-20 \%$ to $17 \%$ for the zero-to-zero method.

Note that the "expected" reflection height usually refers to the $h$ ' parameter of the loglinear Wait and Spies electron density profile, which generally cannot be directly compared to the geometrically derived reflection height $\left(\mathrm{h}_{1}\right)$. Thus, the absolute ground-truth for testing our method is actually not available. It is important to note that, even if our absolute heights are in error (overestimates), the difference in heights for strokes within the same flash, which is the main finding of this paper, should still hold. 


\subsection{Influence of source current frequency content}

We will show here that the observed difference in reflection heights for first and subsequent strokes cannot be explained by the difference in frequency content of typical first and typical subsequent return-stroke currents. Those current waveforms are reproduced in Figures 8a and b, respectively. Note that the 10-to-90\% risetime and time to half-peak value for first strokes are considerably larger than their counterparts for subsequent strokes. The corresponding frequency spectra are found in Figures 5a and b, respectively, of Heidler and Hopf [1994]. For first strokes, the spectrum extends to about $100 \mathrm{kHz}$ and to about $10 \mathrm{MHz}$ for subsequent strokes. Results of FDTD calculations of VLF electric field waveforms for the simulated daytime ionosphere are presented in Figure 9. Clearly, the delays of the first sky wave relative to the ground wave for source current waveforms typical for first and subsequent strokes are essentially the same.

The waveforms presented in Figure 9 were computed for a 5-km long vertical lightning channel using a FDTD model of VLF propagation in the Earth-ionosphere waveguide [Hu and Cummer, 2006]. Curved ground geometry and arbitrary vertical inhomogeneity in the electron density profile were included. We assumed an exponential electron density profile with $h^{\prime}=73 \mathrm{~km}$ and $\beta=0.40 \mathrm{~km}^{-1}$, which are parameters that give a good statistical match to daytime sferics [Han and Cummer, 2010; Han et al., 2011] (see the first reference for the functional form).

The VLF waveforms shown in Figure 9 are to be compared to the observed VLF (100 Hz - $25 \mathrm{kHz})$ waveforms presented in Figure 7 of Haddad et al. [2012]. It follows from this comparison that the observed significant difference in skywave delays for first and subsequent strokes cannot be explained by the difference in frequency content of first and subsequent return-stroke currents.

Note that the calculated ground wave for the first stroke shown in Figure 9 does not reproduce the pronounced opposite polarity overshoot seen in measured waveforms. We attribute this discrepancy to the limitations in specifying the source in the employed FDTD model (although the long fall time of the first-stroke current waveform also served to reduce the opposite-polarity overshoot). The main point, however, appears to be clear: the model-predicted skywave delay is essentially the same for first and subsequent strokes. It is unlikely that the main point is influenced by the model inability to reproduce the overshoot for first strokes. 
Perhaps even more important here is our observation that reduction in ionospheric reflection height

was observed following either first or subsequent strokes, which argues against the notion that the results summarized in Table 1 are materially influenced by the difference in current frequency content of first and subsequent strokes.

The well-known difference in frequency spectra of EMPs produced by first and subsequent strokes (larger higher-frequency content for subsequent strokes) is discussed in section 5.

\subsection{Nighttime vs. daytime waveforms}

First, we will show in Figures 10 and 11, two examples of daytime multiple-stroke flashes. Note that all electric field waveforms in a given flash are normalized relative to the peak of the first-returnstroke waveform. Wideband vertical electric field waveforms of two negative returns strokes in the same flash that occurred at a distance of $228 \mathrm{~km}$ are shown on a $600-\mu$ s time scale in Figure 10. The waveforms were recorded at about 16:42 local time. The vertical broken line indicates the position of the maximum of the first skywave for stroke 1. The NLDN-reported peak current (I) and the preceding interstroke interval $(\Delta t)$ are also shown. Note that the delay of the first skywave with respect to the ground wave, $t_{1}$, which was used for estimating the corresponding ionospheric reflection height, $h_{1}$, is smaller for stroke 2, which is indicative of an apparent decrease (by $5 \mathrm{~km}$ in this case) of the ionospheric reflection height. Another example of daytime flash, this time composed of 6 strokes, is shown in Figure 11. Note that the maxima of the first skywaves for strokes 2, 3, and 4, exhibit progressively smaller delays relative to the ground wave maximum, which corresponds to progressively lower ionospheric reflection heights, 88, 84, and $69 \mathrm{~km}$ for strokes 2,3 , and 4, respectively. For strokes 5 and 6, which were not located by the NLDN and for which the distance was assumed to be the same as that for strokes 1 through 4 , the reflection height appears to increase to 81 $\mathrm{km}$ and then decrease to $67 \mathrm{~km}$. We cannot rule out the possibility that strokes 5 and 6 are not part of the same flash, but consider this highly unlikely, because, among other things, the waveform of stroke 6 is very similar to that of stroke 4 , suggesting the same channel to ground.

Next, we will show an example of nighttime waveforms. Shown in Figure 12 are electric field waveforms of three strokes of a flash that occurred at 10:00 p.m. local time at distances of 90-91 km. Note that for the first two strokes skywave delays with respect to the ground waves are essentially the 
same which means that there is no appreciable change in ionospheric reflection height, whereas the third-stroke skywave delay suggests a decrease of $10 \mathrm{~km}$ in ionospheric reflection height.

We will show in the next section that a decreasing trend in ionospheric reflection height during individual multiple-stroke flashes is less likely to be observed under nighttime conditions than under daytime conditions.

\subsection{Different patterns in reflection height change within individual flashes}

For analyzing the apparent reflection height change patterns only flashes which have more than one stroke were considered. We examined a total of 54 daytime and 11 nighttime flashes (up to six and three strokes per flash, respectively), containing a total of 211 (65 first and 146 subsequent) NLDNlocated strokes with identifiable/measurable skywaves. Additionally, for 19 strokes (all subsequent) not located by the NLDN we assumed the distances to be the same as those for other strokes in the flash. Thus, the total numbers of first and subsequent strokes involved in the pattern analysis were 65 and 165 , respectively.

We classified apparent reflection height change patterns into four categories:

(a) Monotonic decrease in height: Subsequent strokes in a flash show a monotonic decrease in reflection height with increasing stroke order.

(b) Non-monotonic variation: Subsequent strokes in a flash sequentially show opposite trends in changing reflection height.

(c) No change: The reflection height remains essentially the same for all strokes in the flash.

(d) Monotonic increase: Subsequent strokes show a monotonic increase in reflection height.

Clearly, only flashes with three or more strokes could exhibit non-monotonic variation. Apparent reflection height changes were measured in two ways: with respect to the immediately preceding stroke (first or subsequent) and with respect to the first stroke in the flash.

We now discuss uncertainties in estimating reflection heights based on the peak-to-peak method (see Figure 5). Under daytime conditions, the skywave waveform is dispersed and smoothed (due to absorption of higher frequency components), making it difficult to determine the exact position of the peak. For the nighttime waveforms, the peaks are usually sharper and more clearly seen, due to the 
thinner high-absorption D-layer, which makes the ionosphere a much better reflector at night. The difference between the nighttime and daytime waveforms is clearly seen in Figure 2.

For daytime waveforms, we selected the midpoint of the relatively flat top portion of skywave in measuring the peak-to-peak time interval. This approach is associated with some error in $t_{1}$ due to uncertainty in the position of skywave peak on the time axis, which leads to an uncertainty in estimated ionospheric reflection height. An additional factor is the error in NLDN-reported distance $r$ used in equation (1). We estimated the uncertainties in reflection height $h_{1}$ due to uncertainties in both $t_{1}$ and $\mathrm{r}$. The analysis was performed on 46 first and 110 subsequent strokes observed under daytime conditions. Details of this analysis are found in Appendix A. Histogram of uncertainties in reflection height and corresponding statistics are shown in Figure 13. These uncertainties were taken into account in examining the reflection height change patterns. For nighttime waveforms, skywave peaks are sharper and we assumed our peak-to-peak time intervals to be accurate. It is clear from Figure 13, that most of the strokes have uncertainties less than $1 \mathrm{~km}, 88 \%$ of the strokes have uncertainties less than $2 \mathrm{~km}$, and $97 \%$ less than $3 \mathrm{~km}$.

We now examine different patterns for 54 daytime multiple-stroke flashes, first assuming that the computed $h_{1}$ values are accurate and then taking into account uncertainties in those values. As stated earlier, we consider two types of changes in reflection height: with respect to the immediately preceding stroke (first or subsequent) and with respect to the first stroke of the flash.

Changes in reflection height with respect to the preceding stroke are summarized in Table 2 for the following three cases (a) without considering uncertainty in $h_{1}$, (b) assuming 2-km uncertainty, and (c) assuming 3-km uncertainty. Without uncertainty, 57\% show a monotonic decrease in height, 39\% nonmonotonic variation, $2 \%$ no change, and $2 \%$ monotonic increase. For $2-\mathrm{km}$ uncertainty, $76 \%$ show monotonic decrease, $20 \%$ non-monotonic variation, $2 \%$ no change, and $2 \%$ monotonic increase. For 3$\mathrm{km}$ uncertainty, $83 \%$ exhibit monotonic decrease and $13 \%$ non-monotonic variation. The occurrence of the decreasing pattern becomes larger with uncertainties in $\mathrm{h}_{1}$, because of a decrease in the occurrence of the non-monotonic-variation pattern.

A similar analysis was done for changes in reflection height with respect to the first stroke in the flash. Results are shown in Table 3. An important observation from this Table is that more than 90\% of the flashes show a decrease in reflection height, regardless of uncertainty in $h_{1}$. 
We also analyzed the reflection height change patterns for 11 nighttime flashes. Results are presented in Table 4. For nighttime flashes, patterns in reflection height changes with respect to the immediately preceding stroke are: $46 \%$ - no change, $27 \%$ - monotonic decrease, and $27 \%$ - nonmonotonic variation. When changes are measured with respect to the first stroke of the flash, $54 \%$ of flashes showed monotonic decrease and $46 \%$ no change. Clearly, the decreasing trend that is dominant under daytime conditions, is not dominant at night.

It is worth noting that in the 11 nighttime flashes all strokes exhibited identifiable/measurable skywaves, while in the 54 daytime flashes there were strokes whose skywaves could not be identified or could not be used for estimating $h_{1}$ (were unmeasurable). Specifically, out of 54 daytime flashes, 8 contained strokes for which the reflection heights immediately before and immediately after the stroke were unknown. As a result, the actual patterns for those 8 flashes could differ from those used in compiling Tables 2 and 3. To check this, we repeated the analysis for 46 daytime flashes in which reflection heights were known for all consecutive strokes with respect to preceding and first strokes. Results are presented in Tables S1 and S2, for the case of neglecting uncertainty in $h_{1}$. From comparison of Tables 2a and S1 and Tables 3a and S2, we conclude that the missing information about some of the strokes did not result in material differences in the overall results.

Note that in 5 out of the 46 daytime flashes there were strokes with unknown $h_{1}$ (for reasons given above) that occurred after multiple strokes with known $h_{1}$, so that for these flashes the patterns are correct (cannot be altered for the considered strokes), but may be incomplete (should be viewed as partial). The partial patterns were included to increase the sample size.

\subsection{Change in reflection height as a function of return-stroke peak current and preceding interstroke interval}

A total of 54 first and 51 subsequent strokes in 54 multiple-stroke daytime flashes were considered for the peak current (I) analysis and 79 subsequent strokes in 54 flashes with at least 3 strokes for the interstroke interval $(\Delta t)$ analysis. There is essentially no correlation between $\Delta h$ and I. Similarly, there is essentially no correlation between $\Delta h$ and $\Delta t$, although the mean value of $\Delta h$ for the $50-100 \mathrm{~ms}$ range (most common interstroke intervals) is $-4.4 \mathrm{~km}$ vs. closer-to-zero mean values for both smaller and larger $\Delta t$. The reasons for the latter result is presently unclear (perhaps the recovery time is longer 
than even the longest interstroke intervals), while the possible meaning of the lack of correlation between $\Delta h$ and I is discussed in section 5 .

\subsection{Correlation between magnitudes of first skywave and ground wave}

At distances greater than about $700 \mathrm{~km}$, the ground wave in electric field waveforms is indiscernible due to being dwarfed by less-attenuated ionospheric reflections and cannot be used for inferring source parameters. As a result, global (long-range) lightning locating systems (e.g., GLD 360 [Said et al., 2013]) reporting lightning peak currents have to extract this information from skywaves (from sferics made up of multiple waveguide modes). In order to gain some insight into validity of this general approach we compared magnitudes of first skywaves in our data set to those of their corresponding ground waves. The latter are known to be correlated with their causative currents [e.g., Mallick et al., 2014]. Measurements of magnitudes of ground wave and skywave are illustrated in Figure 5, and Figure 14 shows a scatter plot for the skywave electric field peak versus ground wave electric field peak. There is some positive correlation for both first and subsequent strokes, although the scatter is rather large. Determination coefficients $\left(R^{2}\right)$ are 0.37 and 0.15 for first and subsequent strokes, respectively. The corresponding correlation coefficients are 0.61 and 0.38 . The correlation coefficient for first strokes would be lower if two events with the ground wave peaks between 80 and $100 \mathrm{~V} / \mathrm{m}$ were removed.

The geometric mean ratio of groundwave and skywave electric field peaks for 163 first and 131 subsequent strokes is 3.23 , which should be viewed as a lower bound, because many events with nonmeasurable skywaves are not included in this analysis.

\subsection{Ionospheric reflection heights of compact intracloud discharges}

In this section, we examine the ionospheric reflection heights for a pair of compact intracloud discharges (CIDs) separated by $138 \mathrm{~ms}$ that occurred at night at a distance of about $224 \mathrm{~km}$. Electric field signatures of these events were recorded at LOG, using the same instrumentation as that used to acquire other data presented in this paper. Return strokes are generated near ground, while CIDs occur in the upper part of the cloud. As a result, ionospheric reflection signatures of CIDs differ from those 
of return strokes.

For estimating the heights of each CID (h) and its ionospheric reflection $(\mathrm{H})$, a flat earth propagation model was used (see Figure 15). Electric field waveforms of the two CIDs labeled CID1 and CID2, are shown in Figures 16a and b, respectively. For CID1, the estimated values of $\mathrm{h}$ and $\mathrm{H}$ are 8.1 and $90 \mathrm{~km}$, while for CID2 they are 11.5 and also $90 \mathrm{~km}$. Thus, the reflection heights of CID2 and CID1 are the same, which is in contrast with the trend for return strokes in many ground flashes discussed in the preceding sections. Possible reasons for the disparity include the following:

1. The pair of CIDs occurred at night when the apparent lowering of ionospheric reflection height is less likely (see Table 4).

2. Different radiation patterns of CIDs and return strokes (return-stroke radiation is focused upward [e.g., Rakov and Tuni, 2003], while CIDs are similar to Hertzian dipoles [Nag and Rakov, 2010]).

3. Relatively small intensity of CID1 (NLDN-reported peak current of $26.6 \mathrm{kA}$ ).

Additional observations of CID pairs (which occur rarely) are needed to check the generality of the result obtained in this study.

\section{Discussion}

The reflection heights under daytime conditions estimated in this study are appreciably larger than expected (80-90 km vs. expected 70-80 km). We can offer the following explanations. Firstly, many of the events that we labeled "daytime" actually correspond to the day-to-night transition conditions (see Figure S3 in Supplementary Material) when the effective reflection height is highly variable [Smith et al., 2004, Figure 6]. Secondly, we found that the effective reflection height tends to increase with increasing peak current (see Tables 5 and 6). Since our events have peak currents (and associated electromagnetic pulses) that are considerably larger than average (see Figure S2 in Supplementary Material), it is reasonable to expect larger than average reflection heights. Additionally, as noted above one should keep in mind that the "expected" reflection height usually refers to the $h$ ' parameter of the loglinear Wait and Spies electron density profile, which generally cannot be directly compared to the geometrically derived reflection height $\left(\mathrm{h}_{1}\right)$. Note that the expected dependence of penetration depth on frequency is not seen in our data (higher-frequency subsequent-stroke EMPs [e.g., Serhan et al., 1980] appear to reflect at heights that are lower than those for lower-frequency first-stroke EMPs), 
probably due, at least in part, to a stronger dependence on pulse amplitude.

Lightning-generated electromagnetic pulses can produce additional ionization at ionospheric heights [e.g., Taranenko, 1993; Rowland et al., 1996] in the form of elves which are known to create ionospheric height perturbations of several kilometers during nighttime conditions [Inan et al., 2010]. Elves have large, up to a few hundreds of kilometers, radial extent. They can act as local lightningdriven electron sources near the lower boundary of the ionosphere [e.g., Mende et al., 2005]. Farges et al. [2007], who used MF (0.5-1.5 MHz) transmitter signals, reported on lightning-caused perturbations with radii reaching $250 \mathrm{~km}$, and Salut et al. [2013], who used VLF (3-30 kHz) transmitter signals, observed perturbations up to about $400 \mathrm{~km}$ in radius. In both studies, the apparent size of ionospheric disturbances increased with increasing the peak current of the causative lightning discharge. Optical elves last less than $1 \mathrm{~ms}$, but their effects can persist for 10-100 s [Inan et al., 2010], which is much longer than the duration of causative lightning flashes. Thus, one possible explanation for the observed apparent lowering of ionospheric reflection height, which was offered by Haddad et al. [2012], is additional ionization associated with elves. It is worth noting that some of the existing models [e.g., Marshall et al., 2008, 2010] predict that the ionization changes associated with elves are only a few percent of the background electron density. On the other hand, Schmitter [2014] predicted a very significant (in excess of a factor of 2) ionization increase produced at $93 \mathrm{~km}$ altitude at night by EMP of a 50-kA stroke. The corresponding reduction in the apparent reflection height was about $2 \mathrm{~km}$. Clearly, additional work to test and improve models is needed.

It is thought that additional ionization is unlikely at relatively low altitudes under daytime conditions, because of the relatively short mean free path [e.g., Haldoupis et. al., 2013]. However, stronger electromagnetic pulses might be able to propagate to higher altitudes, where the mean free path is longer, and cause ionization there. Indeed, in our data, the ionospheric reflection height tends to increase with increasing peak current (see Tables 5 and 6). In the case of multiple-stroke flashes, there may be cumulative effect in producing additional ionization, leading to the observed progressive decrease in reflection height within individual flashes. We found that the mean cumulative decrease in reflection height for flashes containing four or more strokes is appreciably larger than for two- and three-stroke flashes (see Table S3 in Supplementary Material), which could be interpreted as a 
confirmation of the notion that lightning EMP effects in the ionosphere persist longer than interstroke intervals. Creation of higher-conductivity plasma layers by multiple electromagnetic pulses (EMPs) can be visualized as follows. Ionization occurs just below where a plasma layer reflects the first EMP (although the existing models predict that the ionization typically occurs above the reflection height [e.g., Marshall et al., 2010]), increasing the electron and ion densities at the lower altitude. The following EMP then reflects from the new, lower layer, creating new ionization below the new reflection point, and so on, causing the effective reflecting layer to descend.

It is also possible that the observed difference in reflection heights for first and subsequent strokes is, at least in part, due to the difference in the depth of penetration into the daytime ionosphere of first and subsequent stroke EMPs (subsequent strokes in our data set are more than a factor of 3 less intense than the first ones; see Figure S2). Thus, reflection heights for subsequent strokes may be "normal", while those for first strokes may be larger because of the higher intensity of first strokes. This argument can be extended to explain the apparent decrease in reflection height after subsequent strokes, since there is a tendency for the return-stroke peak current to decrease with stroke order (for 141 daytime flashes with up to four strokes, mean values are 33, 30, and $23 \mathrm{kA}$ for strokes of order of 2,3 , and 4 , respectively). The peak-current contrast among subsequent strokes is lower than between subsequent and first strokes, which apparently explains a higher occurrence of decreasing pattern in $\mathrm{h}_{1}$ changes relative to the first stroke than that relative to the immediately preceding stroke. Note that the alternative explanation (dependence of the EMP penetration depth on source intensity, which tends to decrease with stroke order) appears to be consistent with the observed lack of correlation between the apparent change in reflection height and return-stroke peak current, assuming that there is essentially no effect of the preceding stroke on the ionosphere and that the difference in reflection heights is largely determined by the penetration depth (or intensity) of the following stroke. On the other hand, such correlation is expected for the additional-ionization hypothesis assuming that the potential for producing additional ionization (which largely determines the reflection height of the following stroke) increases with increasing the source current.

The observed effects might be due to both the different EMP penetration depth for strokes of different intensity and additional ionization associated with elves. 
The apparent changes in ionospheric reflection height found in this study differ for daytime and nighttime conditions. The monotonically decreasing pattern within individual flashes was dominant under daytime conditions, but not at night. The less pronounced effect at night might be due to lower peak currents compared to the daytime events in our data set, which means a lower potential for producing elves. Specifically, the geometric mean peak currents for first and subsequent strokes under daytime conditions are 91 and $27 \mathrm{kA}$, respectively, while the corresponding values at night are 75 and $22 \mathrm{kA}$. Also, the virtual absence of the D-layer at night might reduce the difference in heights to which first and subsequent stroke EMPs are able to propagate.

Clearly, more research, including modeling, is needed to better understand the experimental data presented here.

\section{Summary and conclusions}

Ionospheric reflection heights estimated using the zero-to-zero (used by Haddad et al. [2012]) and peak-to-peak (used in present study) methods to measure skywave delay relative to the ground wave were compared. In both cases there was a considerable decrease in average reflection height for subsequent strokes relative to that for first strokes. The standard errors in mean values of reflection height were less than $3 \%$ of the mean value. The observed difference in reflection heights for first and subsequent strokes cannot be explained by the difference in frequency content of first and subsequent return-stroke currents.

Patterns in apparent reflection height changes within individual flashes for 54 daytime and 11 nighttime events at distances ranging from 50 to $330 \mathrm{~km}$ were compared, and significant differences were found. For daytime conditions, the majority of the flashes showed either decrease $(57 \%)$ or non-monotonic variation $(39 \%)$ in reflection height with respect to the immediately preceding stroke. With respect to the first stroke, $91 \%$ of the flashes showed monotonic decrease in height. The trends were similar when uncertainties in reflection height estimates were accounted for. For nighttime flashes, patterns in reflection height changes with respect to the preceding stroke were as follows: $46 \%$ no change, $27 \%$ monotonic decrease, and $27 \%$ non-monotonic variation. When changes were measured with respect to the first stroke, $54 \%$ of nighttime flashes showed monotonic decrease and $46 \%$ no change.

There was no correlation found between the change in reflection height and return stroke peak current or preceding interstroke interval. A moderate correlation (correlation coefficient $=0.61$ ) 
exists between the magnitudes of first return stroke ground wave and its first skywave. For subsequent return strokes, the correlation coefficient is 0.38 .

The observed daytime effects can be explained by (a) the dependence of EMP penetration depth on source intensity, which decreases with stroke order, (b) additional ionization associated with elves, or (c) combination of (a) and (b) above. The less pronounced effect at night is probably due to (a) lower peak currents in our nighttime events and (b) virtual absence of the D-layer at night.

Ionospheric reflection heights for a pair of compact intracloud discharges (CIDs) were estimated, and no change in reflection height after the first event was observed.

\section{Appendix A: Uncertainties in estimating the daytime ionospheric reflection height}

The uncertainty in ionospheric reflection height, $\Delta h_{1}$, caused by uncertainties in both skywave arrival time (relative to the ground wave), $t_{1}$, and distance, $r$, from the lightning channel, was found as error of a function expressed in terms of errors of its arguments [Taylor, 1996]:

$$
\Delta h_{1}=\sqrt{\left(\frac{d h_{1}}{d t_{1}} \Delta t_{1}\right)^{2}+\left(\frac{d h_{1}}{d r} \Delta r\right)^{2}}
$$

where $\Delta t_{1}$ and $\Delta r$ are uncertainties in $\mathrm{t}_{1}$ and $\mathrm{r}$, respectively. The derivatives, $\mathrm{dh}_{1} / \mathrm{dt}_{1}$ and $\mathrm{dh}_{1} / \mathrm{dr}$, were evaluated by differentiating equation (1) with respect to $t_{1}$ and $\mathrm{r}$, respectively. Values of $\Delta t_{1}$ were estimated by drawing a horizontal line tangential to the skywave field waveform, and values of $\Delta r$ were assumed to be equal to median location errors reported by the NLDN. Typical values of $\Delta t_{1}$ and $\Delta r$ were from a few to tens of microseconds and about few hundreds of meters, respectively.

Uncertainties in $h_{1}$ due to uncertainties in $\mathrm{r}$ were found to be negligible. Uncertainties in $h_{1}$ due to uncertainties in $t_{1}$ were evaluated for a total of 156 daytime strokes and results are presented in Figure 13. These results were used in evaluating different ionospheric reflection height change patterns in individual daytime flashes in section 4.4. Note that we did not try to consider different combinations of uncertainties for individual strokes in a flash. Our approach was as follows. We, in effect, tested the hypothesis that the reflection heights for all strokes in a flash are actually the same, and the observed differences are due to uncertainties in measuring $t_{1}$. In this approach, the differences in $h_{1}$ for consecutive strokes were compared with a given uncertainty in $h_{1}$. If the difference in $h_{1}$ was 
greater than the uncertainty, the difference was considered real, and if the difference in $\mathrm{h}_{1}$ was smaller than the uncertainty, it was set to zero. Thus, relatively small variations in $h_{1}$ within a flash were eliminated and relatively large ones retained. The result was a decrease of the number of nonmonotonic-variation patterns with increasing the uncertainty. 
Acknowledgments. This work was supported in part by NSF Grant ATM-0852869, GRF Grant No. 14.B25.31.0023, and DARPA NIMBUS program. Useful discussions at different stages of this study with T. Farges, C. Haldoupis, R. Moore, R. Marshall, A. Jacobson, and E. Schmitter are acknowledged. The authors thank two anonymous reviewers for their helpful comments.

\section{References}

Budden, K. G., (1988), The propagation of radio waves, Cambridge University Press, Cambridge, UK.

Farges, T., E. Blanc, and M. Tanguy (2007), Experimental evidence of D region heating by lightninginduced electromagnetic pulses on MF radio links, J. Geophys. Res., vol. 112, A10302, doi:10.1029/2007JA012285.

Ginzburg, V. L., (1970), The propagation of electromagnetic waves in plasmas, Pergamon Press, Oxford, UK.

Haddad, M. A., V. A. Rakov, and S. A. Cummer (2012), New measurements of lightning electric fields in Florida: Waveform characteristics, interaction with the ionosphere, and peak current estimates, J. Geophys. Res., 117, D10101, doi: 10.1029/2011JD017196.

Haldoupis, C., M. Cohen, E. Arnone, B. Cotts, and S. Dietrich (2013), The VLF fingerprint of elves: Step-like and long-recovery early VLF perturbations caused by powerful CG lightning EM pulses, Geophys. Res. Lett. , 118, 5392-5402, doi: 10.1002/jgra.50489.

Han, F., S. A. Cummer, J. Li, and G. Lu (2011), Daytime ionospheric D region sharpness derived from VLF radio atmospherics, J. phys. Res., 116, A05314, doi: 10.1029/2010JA016299.

Han, F., and S. A. Cummer (2010), Midlatitude nighttime D region ionosphere variability on hourly to monthly time scales, J. Geophys. Res., 115, A09323, doi: 10.1029/2010JA015437.

Heidler, F. and C. Hopf, Lightning current function for LEMP calculation, paper R4-06 presented at 22nd International Conference on Lightning Protection, Tech. Univ. of Budapest, Budapest, Hungary, Sept. 19-23, 1994.

Holle, R. L. (2014), Diurnal Variations of NLDN-Reported Cloud-to-Ground Lightning in the United States, Amer. Meteor. Soc., 142, 1037-1052, doi:10.1175/MWR-D-13-00121.1.

Hu, W., and S. A. Cummer, An FDTD model for low and high altitude lightning-generated EM fields, IEEE Trans. Antennas Propag., vol.54, 1513-1522.

IEC 62305-1, Protection against lightning - Part 1: General principles, (2006), 
International Electrotechnical Commission, Geneva, Edition 1, pages 75-85.

Inan, U. S., S. A. Cummer, and R. A. Marshall (2010), A survey of ELF and VLF research on lightning-ionosphere interactions and causative discharges, J. Geophys. Res., 115, A00E36, doi:10.1029/2009JA014775.

Jacobson, A. R., X.-M. Shao, and E. Lay (2012), Time domain waveform and azimuth variation of ionospherically reflected VLF/LF radio emissions from lightning, Radio Sci., 47, RS4001, doi:10.1029/2012RS004980

Laby, T. H., J. J. McNeill, F. G. Nicholls, and A. F. B. Nickson (1940), Waveform, energy and reflexion by the ionosphere, of atmospherics, Proc. R. Soc. A, 174, 145-163.

Mallick, S., Rakov, V. A., Tsalikis, D., Nag, A., Biagi, C., Hill, D., Jordan, D. M., Uman, M. A., and Cramer, J. A., (2014), On remote measurements of lightning return stroke peak currents, Atmos. Res., 135-136, 306-313, doi: http://dx.doi.org/10.1016/j.atmosres.2012.08.008.

Marshall, R. A. (2014), Effect of self-absorption on attenuation of lightning and transmitter signals in the lower ionosphere, J. Geophys. Res. Space Physics, 119, 4062-4076, doi:10.1002/2014JA019921.

Marshall, R. A., U. S. Inan, and T. W. Chevalier (2008), Early VLF perturbations caused by lightning EMP-driven dissociative attachment, J. Geophys. Res., 35, L21807, doi: 10.1029/2008GL035358.

Marshall, R. A., U. S. Inan, and V. S. Glukhov (2010), Elves and associated electron density changes due to cloud-to-ground and in-cloud lightning discharges, J. Geophys. Res., 115, A00E17, doi:10.1029/2009JA014469.

McDonald, T. B., Uman, M. A., Tiller, J. A., and Beasley, W. H., (1979), Lightning location and lower-ionospheric height determination from two-station magnetic field measurements, J. Geophys. Res., 84, 8C0739.

Mende, S. B., H. U. Frey, R. R. Hsu, T. Su, A. B. Chen, L. C. Lee, D. D. Sentman, Y. Takahashi, and H. Fukunishi (2005), D region ionization by lightning-induced electromagnetic pulses, J. Geophys. Res., 110, A11312, doi:10.1029/2005JA011064.

Nag, A., and V. A. Rakov (2010), Compact intracloud lightning discharges: 1. Mechanism of electromagnetic radiation and modeling, J. Geophys. Res., 115, D20102, doi: 10.1029/2010JD014235.

Pavlov A.V., (2014), Photochemistry of ions at D-region altitudes of the ionosphere: A review, Surv. 
Geophys., vol. 35, 259-334, doi: 10.1007/s10712-013-9253-z.

Rakov, V. A., (2013), The physics of lightning, Surv. Geophys., vol. 34, No. 6, Nov. 2013, pp. 701729, doi: 10.1007/s10712-013-9230-6.

Rakov, V. A., Mallick, S., Nag, A., and Somu, V. B., (2014), Lightning Observatory in Gainesville (LOG), Florida: A review of recent results, Electr. Power Syst. Res., doi: http://dx.doi.org/10.1016/j.espr.2014.02.037.

Rakov, V. A., and W. G. Tuni, (2003), Lightning electric field intensity at high altitudes: Inferences for production of elves, J. Geophys. Res., 108(D20), 4639, doi: doi:10.1029/2003JD003618.

Rakov, V. A., and M. A. Uman (2003), Lightning: Physics and Effects, 687 pp., Cambridge Univ. Press, Cambridge, U. K.

Ratcliffe, J.A. (1959), The magneto-ionic theory and applications to the ionosphere, Cambridge, UK: Cambridge University Press.

Rowland, H. L., R. F. Fernsler, and P. A. Bernhardt (1996), Breakdown of the neutral atmosphere in the D region due to lightning driven electromagnetic pulses, J. Geophys. Res., 101(A4), 7935-7945, doi: 10.1029/95JA03519.

Said, R. K., M. B. Cohen, and U. S. Inan (2013), Highly intense lightning over the oceans: Estimated peak currents from global GLD360 observations, J. Geophys. Res. Atmos., 118, 6905-6915, doi:10.1002/jgrd.50508.

Said, R. K., U. S. Inan, and K. L. Cummins (2010), Long-range lightning geolocation using a VLF radio atmospheric waveform bank, J. Geophys. Res., 115, D23108, doi: 10.1029/2010JD013863.

Salut, M. M., M. B. Cohen, M. A. M. Ali, K. L. Graf, B. R. T. Cotts, and S. Kumar (2013), On the relationship between lightning peak current and Early VLF perturbations, J. Geophys. Res. Space Physics, 118, 7272-7282, doi:10.1002/2013JA019087.

Schmitter, E. D. (2014), Remote sensing and modeling of lightning caused long recovery events within the lower ionosphere using VLF/LF radio wave propagation, Adv. Radio Sci., 12, 241-250, doi:10.5194/ars-12-241-2014.

Schonland, B.F.J., Elder, J.S., Hodges, D.G., Phillips, W.E., and van Wyk, J.W. 1940. The waveform of atmospherics at night. Proc. Roy Soc. A 176:180-202.

Serhan, G. I., M. A. Uman, D. G. Childers, and Y. T. Lin (1980), The RF spectra of first and subsequent lightning return strokes in the 1-200 km range, Radio Sci., 15, 1089 - 1094, doi:10.1029/RS015i006p01089. 
Shao, X., E.H. Lay, and A. R. Jacobson (2013), Reduction of electron density in the night-time lower ionosphere in response to a thunderstorm, Nature Geosci., 6, doi: 10.1038/ngeo1668.

Shao, X., E.H. Lay, and A. R. Jacobson (2014), Ionospheric variation in response to lightning discharges and their parental thunderstorms, paper presented at $15^{\text {th }}$ International Conference on Atmospheric Electricity, Norman, Oklahoma, USA.

Smith, D. A., X. M. Shao, D. N. Holden, C. T. Rhodes, M. Brook, P. R. Krehbiel, M. Stanley, W. Rison, and R. J. Thomas (1999), A distinct class of isolated intracloud lightning discharges and their associated radio emissions, J. Geophys. Res., 104(D4), 4189-4212, doi:10.1029/1998JD200045.

Smith, D. A., M. J. Heavner, A. R. Jacobson, X. M. Shao, R. S. Massey, R. J. Sheldon, and K. C. Wiens (2004), A method for determining intracloud lightning and ionospheric heights from VLF/LF electric eld records, Radio Sci., 39, RS1010, doi: 10.1029/2002RS002790.

Spitzer, L., Jr., (1962), Physics of fully ionized gases, $2^{\text {nd }}$ edition, Interscience publishers, New York.

Stix, T. H., (1962), The theory of plasma waves, McGraw-Hill, New York.

Taranenko, Y.N., Inan, U.S. and Bell, T.F. (1993), Interaction with the lower ionosphere of electromagnetic pulses from lightning: Heating, attachment, and ionization, Geophys. Res. Lett., 20, doi: 10.1029/93GL01696.

Taylor, R. J. (1996), The study of uncertainties in physical measurements, University Science Books, 2nd edition.

Yashunin, S. A., E. A. Mareev, and V. A. Rakov (2007), Are lightning M components capable of initiating sprites and sprite halos?, J. Geophys. Res., 112, D10109, doi:10.1029/2006JD007631.

Yeh, K. C., and Liu, C. H., (1972), Theory of ionospheric waves, Academic Press, New York. 


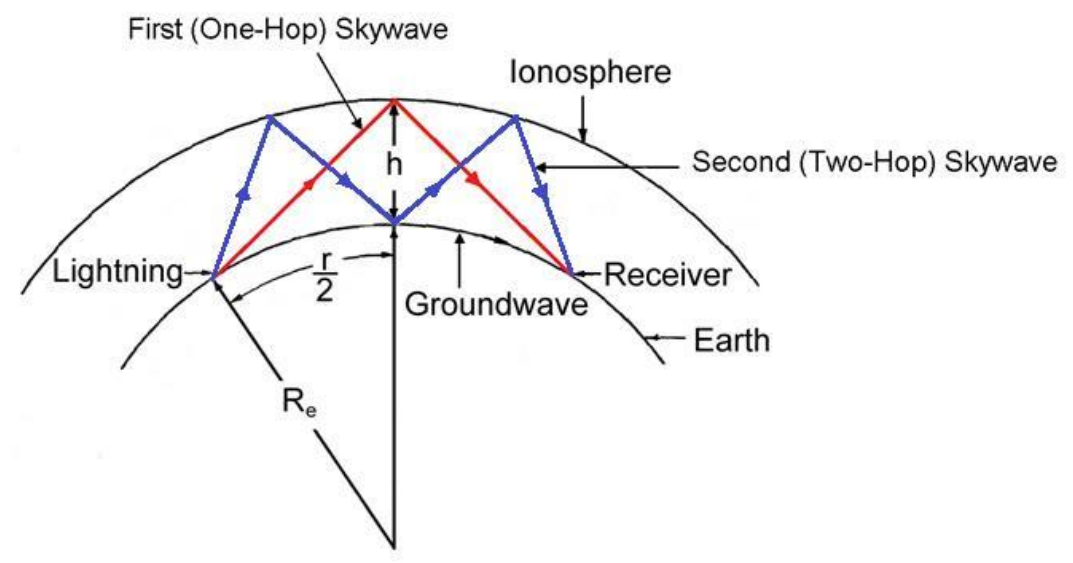

Figure 1: Schematic representation of electromagnetic signal propagation in the Earth-ionosphere waveguide. Adapted from McDonald et al. [1979].
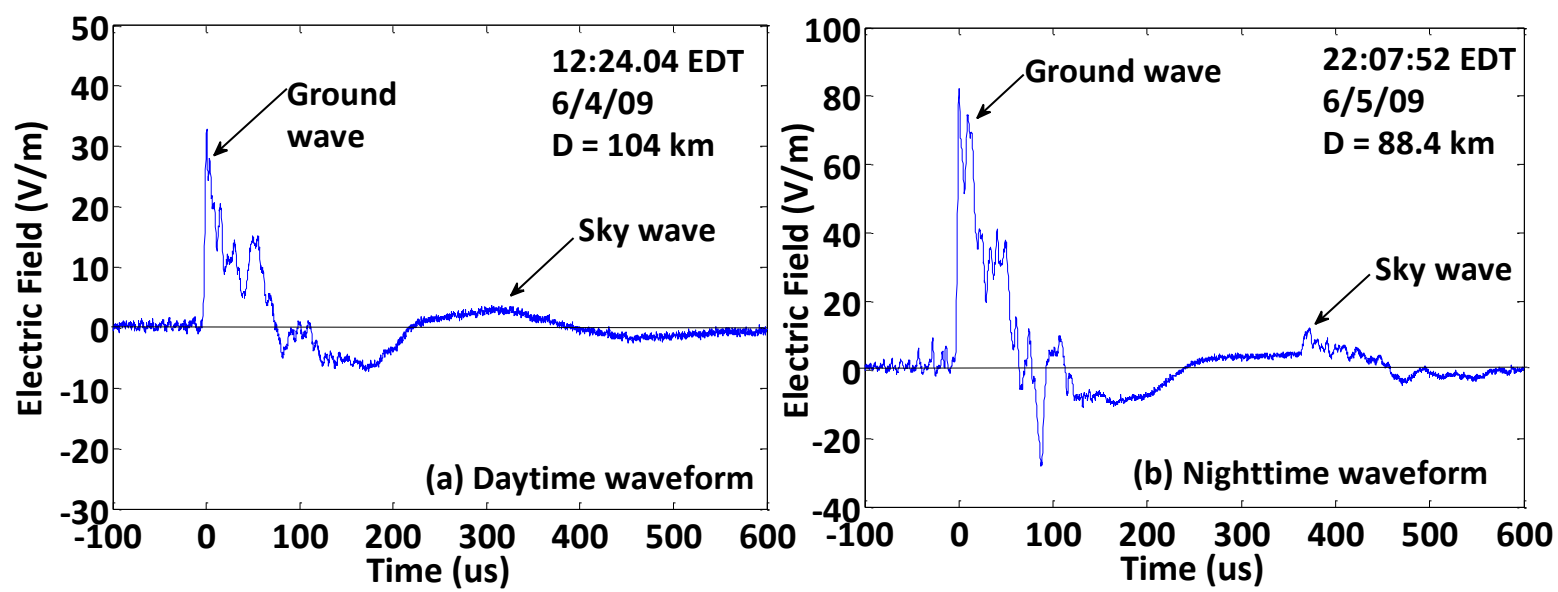

Figure 2: Examples of (a) daytime and (b) nighttime wideband electric field waveforms produced by first return strokes in negative cloud-to-ground lightning at distances of 104 and $88.4 \mathrm{~km}$, respectively. The waveforms were recorded at the Lightning Observatory in Gainesville (LOG), Florida. 


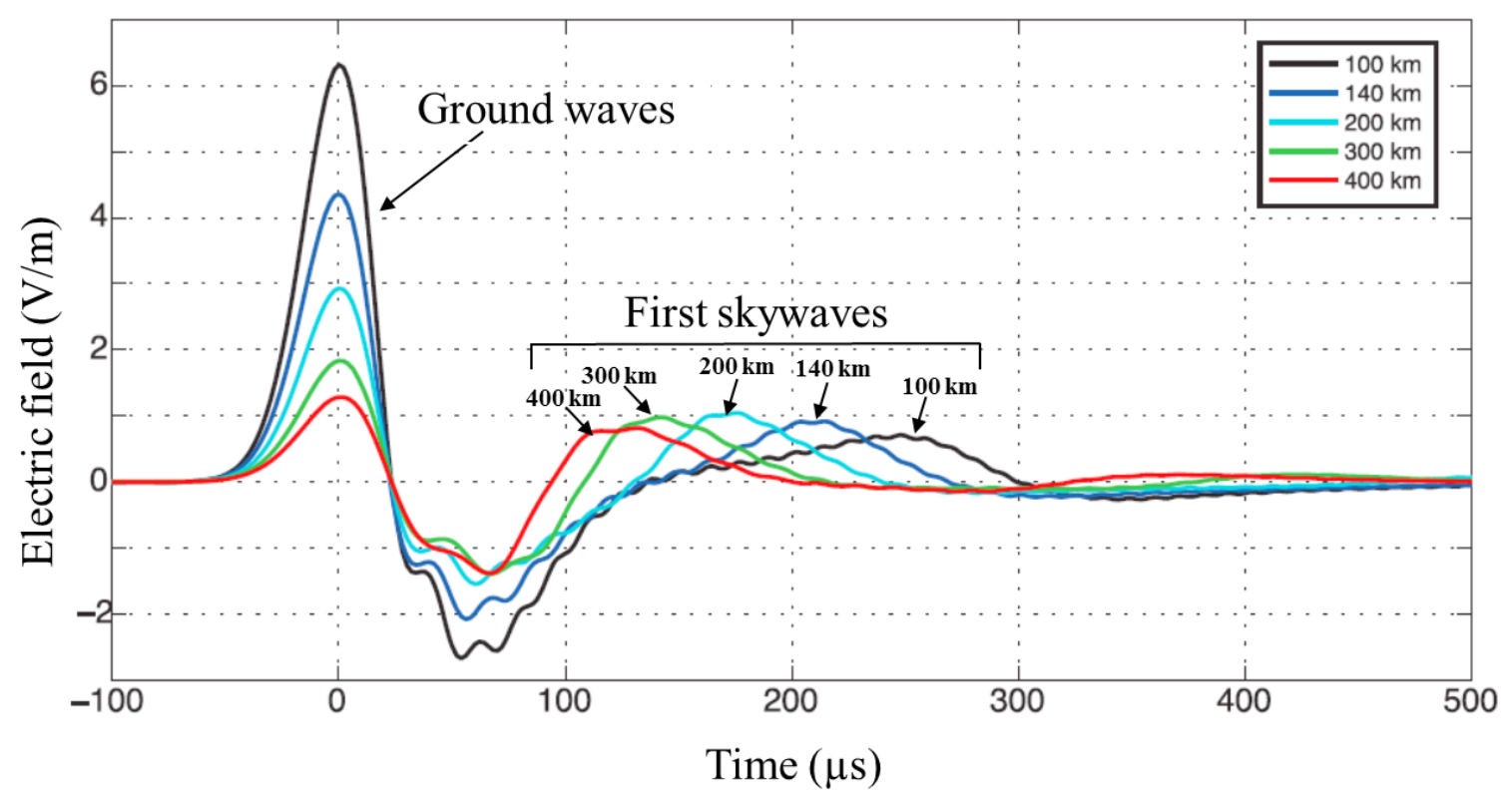

\begin{tabular}{|c|c|c|c|c|c|}
\hline \multirow{3}{*}{ Distance $(\mathrm{km})$} & \multicolumn{4}{|c|}{ Method to measure $t_{1}$} & \multirow{3}{*}{$\begin{array}{c}\text { Time of flight for } \\
\mathrm{h}_{1}=73 \mathrm{~km} \\
(\mu \mathrm{s})\end{array}$} \\
\hline & \multicolumn{2}{|c|}{ Peak-to-peak } & \multicolumn{2}{|c|}{ Zero-to-zero } & \\
\hline & $\mathrm{t}_{1}(\mu \mathrm{s})$ & $\mathrm{h}_{1}(\mathrm{~km})$ & $\mathrm{t}_{1}(\mu \mathrm{s})$ & $\mathrm{h}_{1}(\mathrm{~km})$ & \\
\hline 100 & 246 & 71 & 180 & 58 & 258 \\
\hline 140 & 210 & 73 & 180 & 66 & 210 \\
\hline 200 & 172 & 75 & 168 & 74 & 162 \\
\hline 300 & 142 & 79 & 148 & 81 & 117 \\
\hline 400 & 120 & 81 & 134 & 86 & 93 \\
\hline
\end{tabular}

Figure 3: FDTD-computed VLF (up to about $30 \mathrm{kHz}$ ) vertical electric field waveforms for a 5-km long vertical lightning channel and a Gaussian current pulse with a peak of $20 \mathrm{kA}$ at distances ranging from 100 to $400 \mathrm{~km}$. The second positive half-cycle, occurring at earlier times as the distance increases, is a reflection from the simulated daytime ionosphere $\left(h^{\prime}=73 \mathrm{~km}, \beta=0.40 \mathrm{~km}^{-1}\right)$. Given in the table are the corresponding differences in arrival times of the first skywave and the ground wave, $\mathrm{t}_{1}$ (measured using the peak-to-peak and zero-to-zero methods), and the ionospheric reflection height, $h_{1}$, computed using equation (1). The time of flight is the expected $t_{1}$ which corresponds to a curved earth propagation model and expected reflection height of 73 $\mathrm{km}$. 


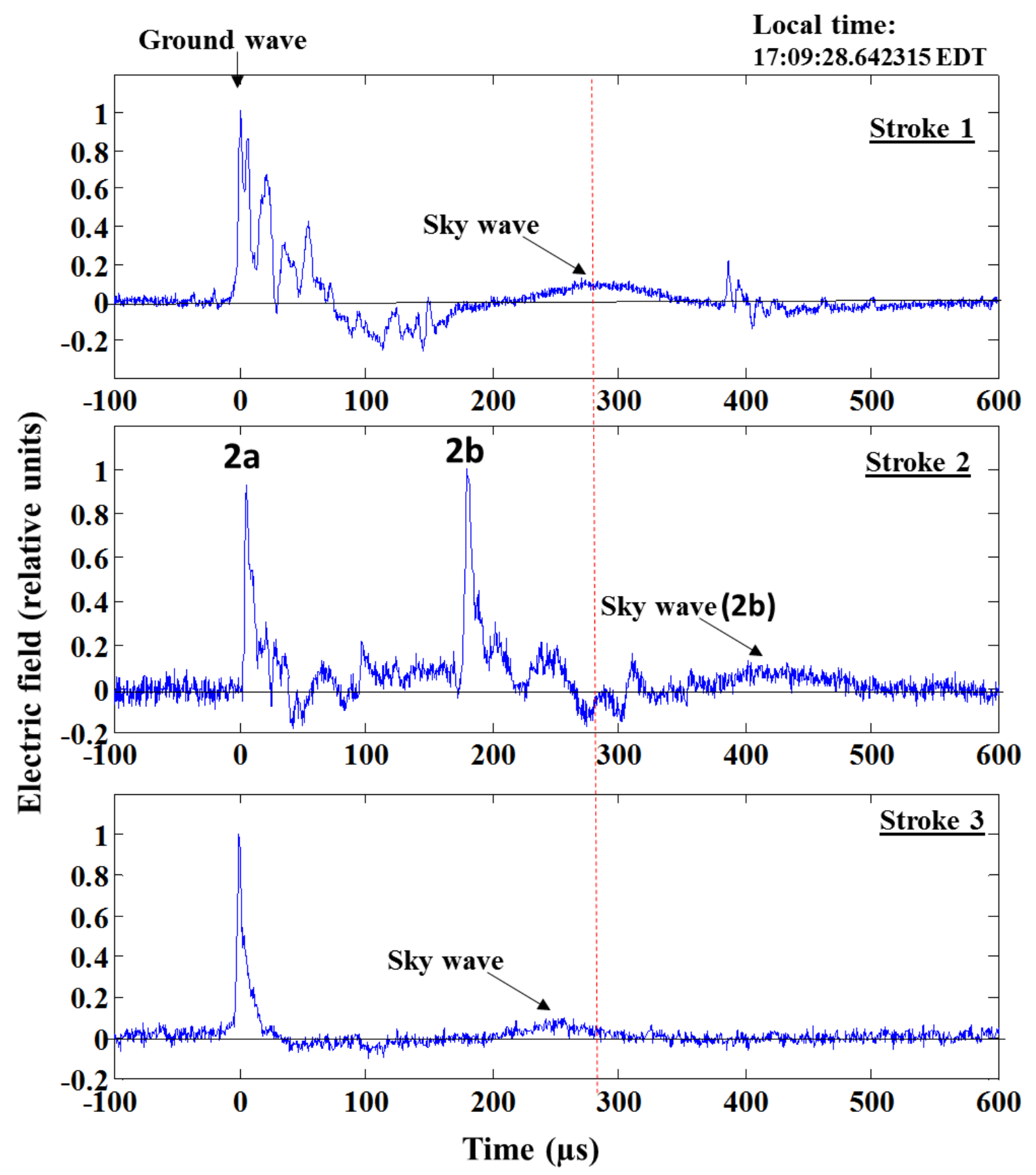

Figure 4: An example of direct wave (apparently produced by a cloud-to-ground stroke $2 b$ that occurred about $178 \mu \mathrm{s}$ after the preceding stroke $2 \mathrm{a}$ ) overlapping the skywave of stroke $2 \mathrm{a}$. This behavior is seen in the middle panel. Also shown in the top and bottom panels are strokes 1 and 3, respectively. The flash occurred at $120 \mathrm{~km}$ on 06/05/2009 at 17:09:28.642315 EDT (first-stroke time). The small pulse at about $400 \mu s$ in the top panel is likely to be direct wave associated with an additional ground contact of stroke 1 . Ground waves of strokes 1, 2a, and 3 are aligned. The vertical broken line indicates the position of the maximum of the first skywave of stroke 1. 


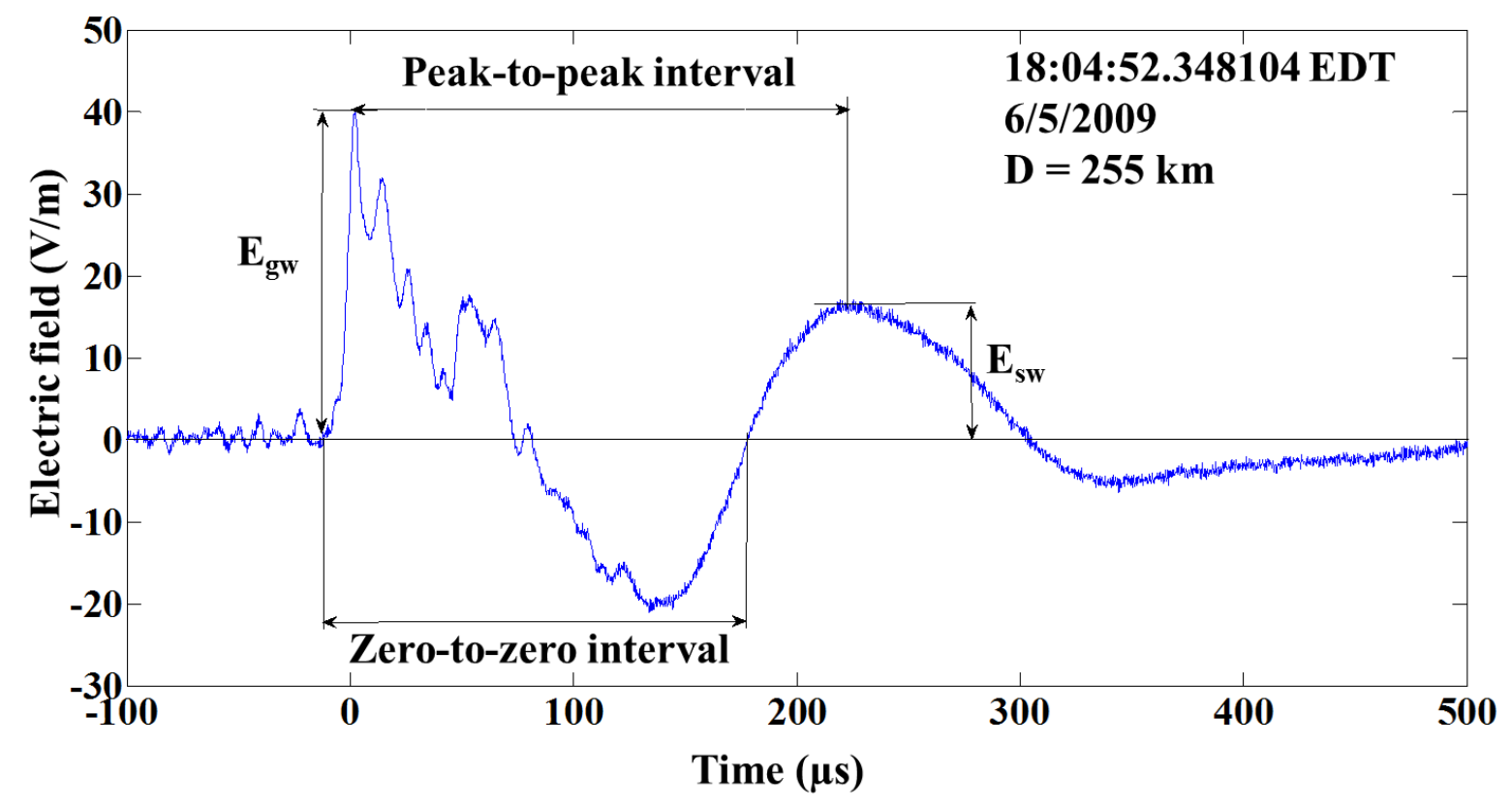

Figure 5: Definitions of two measures of the difference in arrival times of the ground wave and first skywave, based on the use of zero-to-zero and peak-to-peak intervals. Also shown are electric field peaks of the ground wave, $E_{g w}$, and first skywave, $E_{s w}$. 


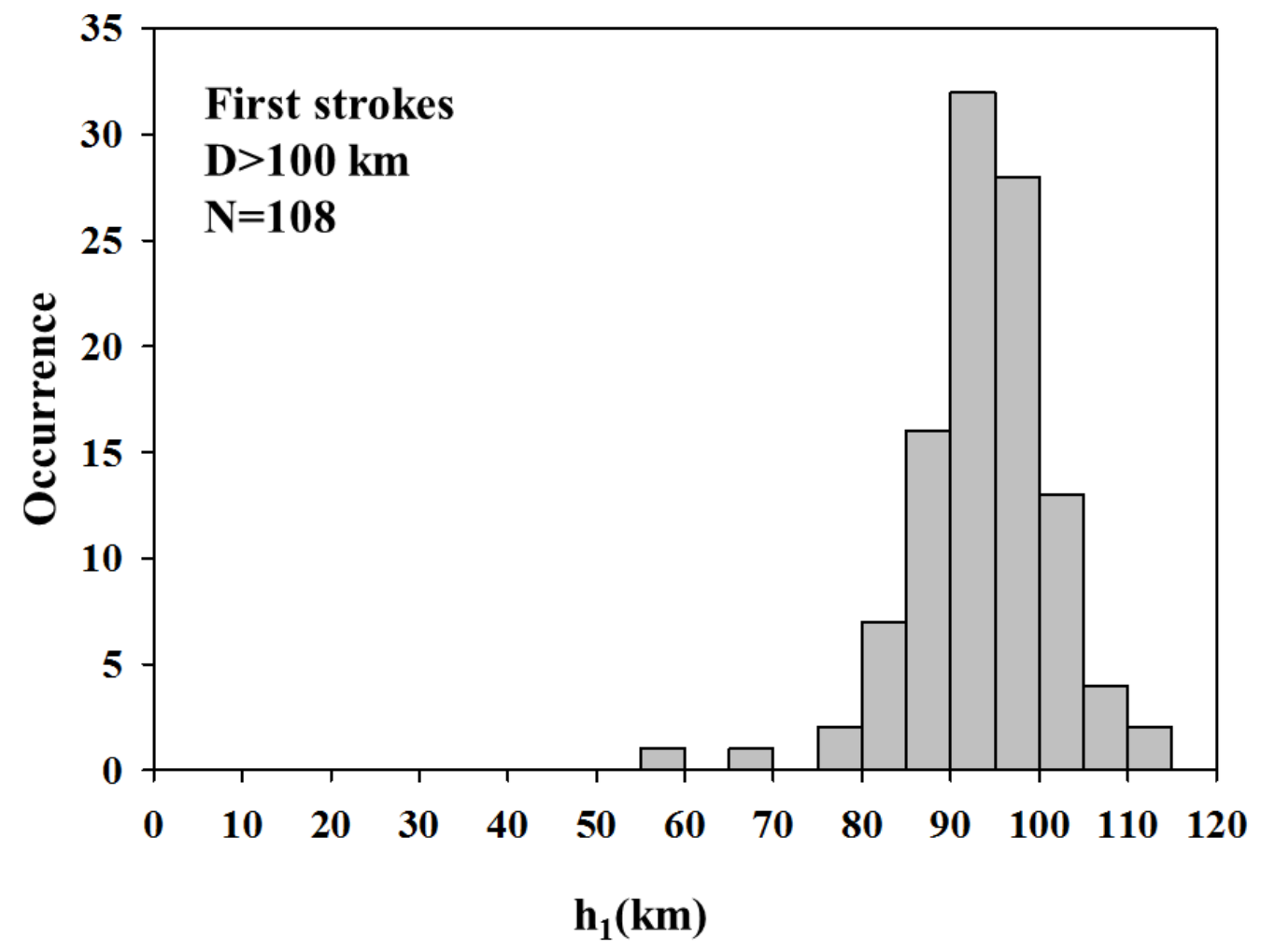

Figure 6: Histogram of ionospheric reflection heights for 108 first strokes estimated using peak-to-peak method to measure $t_{1}$. 


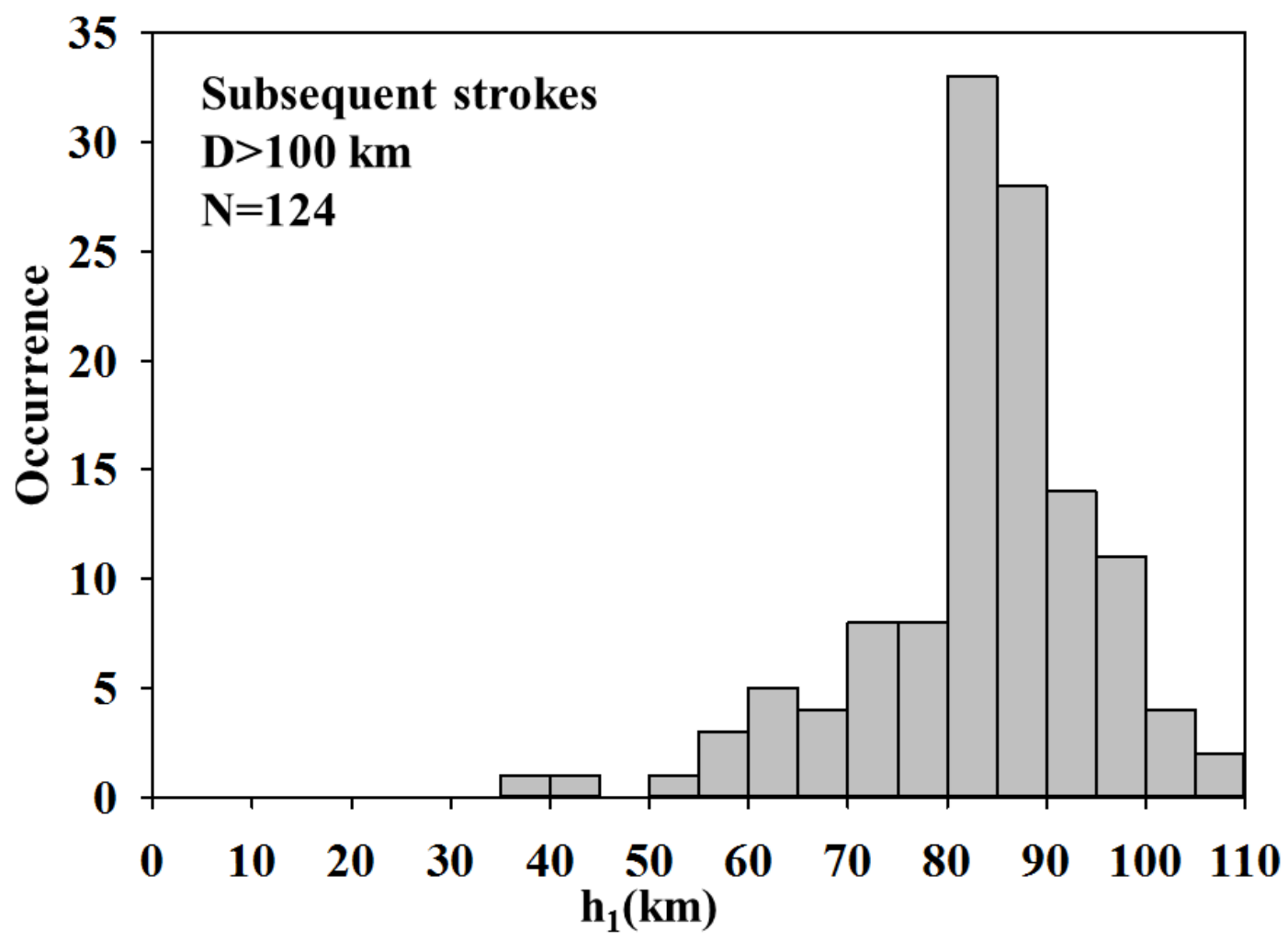

Figure 7: Histogram of ionospheric reflection heights for 124 subsequent strokes estimated using peak-to-peak method to measure $t_{1}$. 

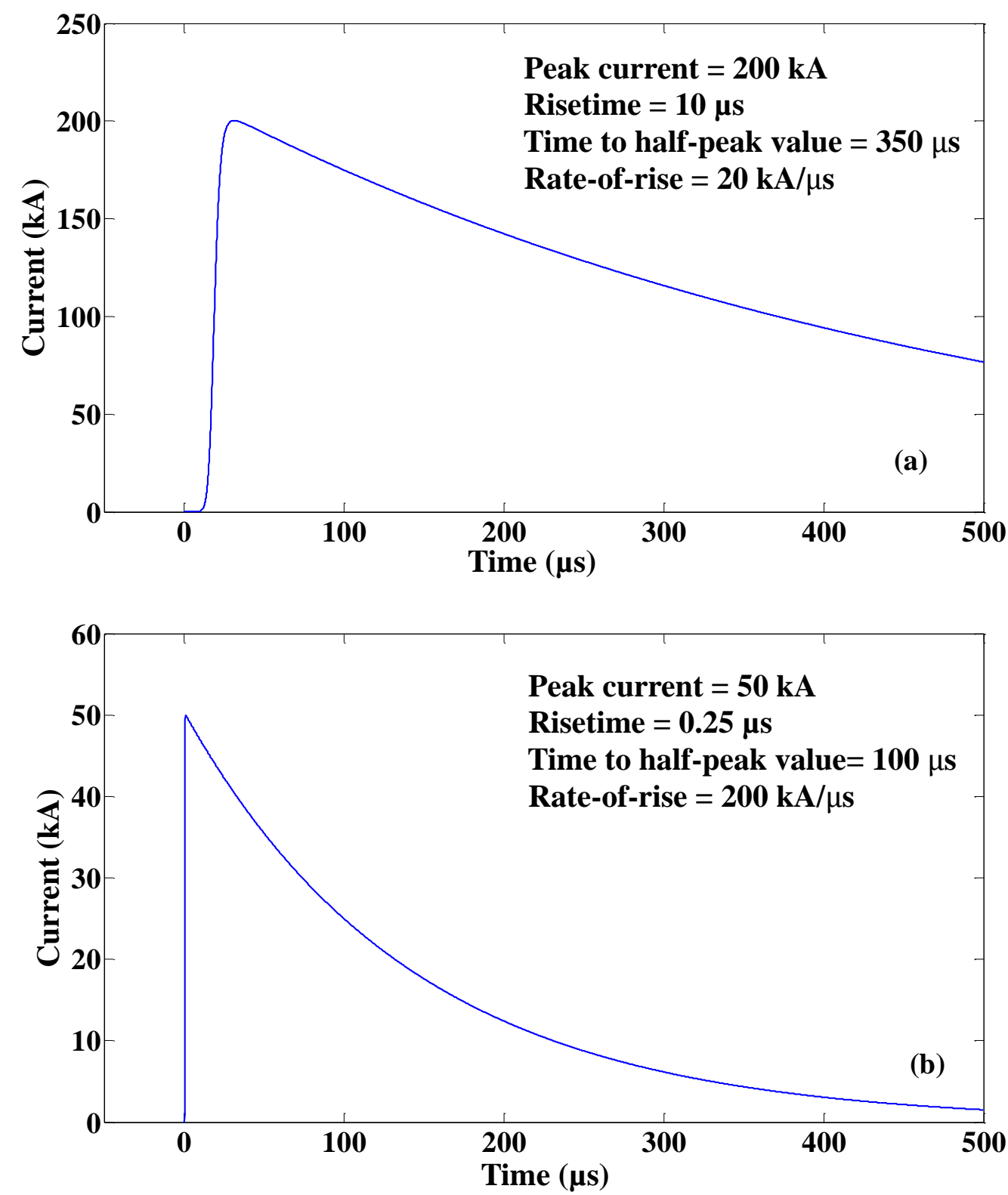

Figure 8: Current waveforms for (a) first and (b) subsequent return strokes adapted by the IEC Lightning Protection Standard [2006]. The risetime was measured between the 10\% and $90 \%$ of peak value levels on the front part of the waveform. The rate-of-rise is the ratio of 0.8 of the peak value and 10-to-90\% risetime. The time to half-peak value was measured between the peak and half-peak value on the tail part of the waveform. The corresponding frequency spectra are found in Heidler and Hopf [1994]. 


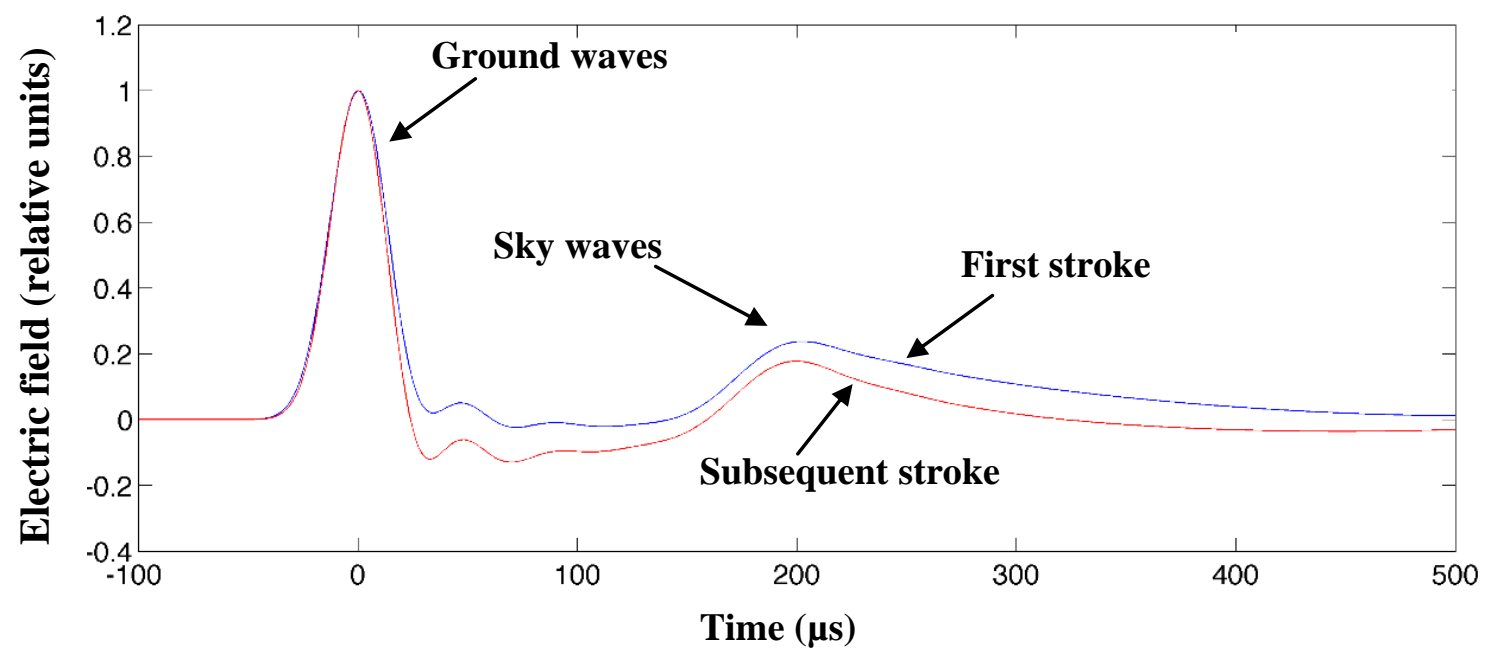

Figure 9: FDTD simulation of VLF signals expected for typical daytime ionospheric conditions at a distance of $170 \mathrm{~km}$ for the typical first and typical subsequent return stroke current waveforms (taken from the IEC Lightning Protection Standard and shown in Figure 8). 


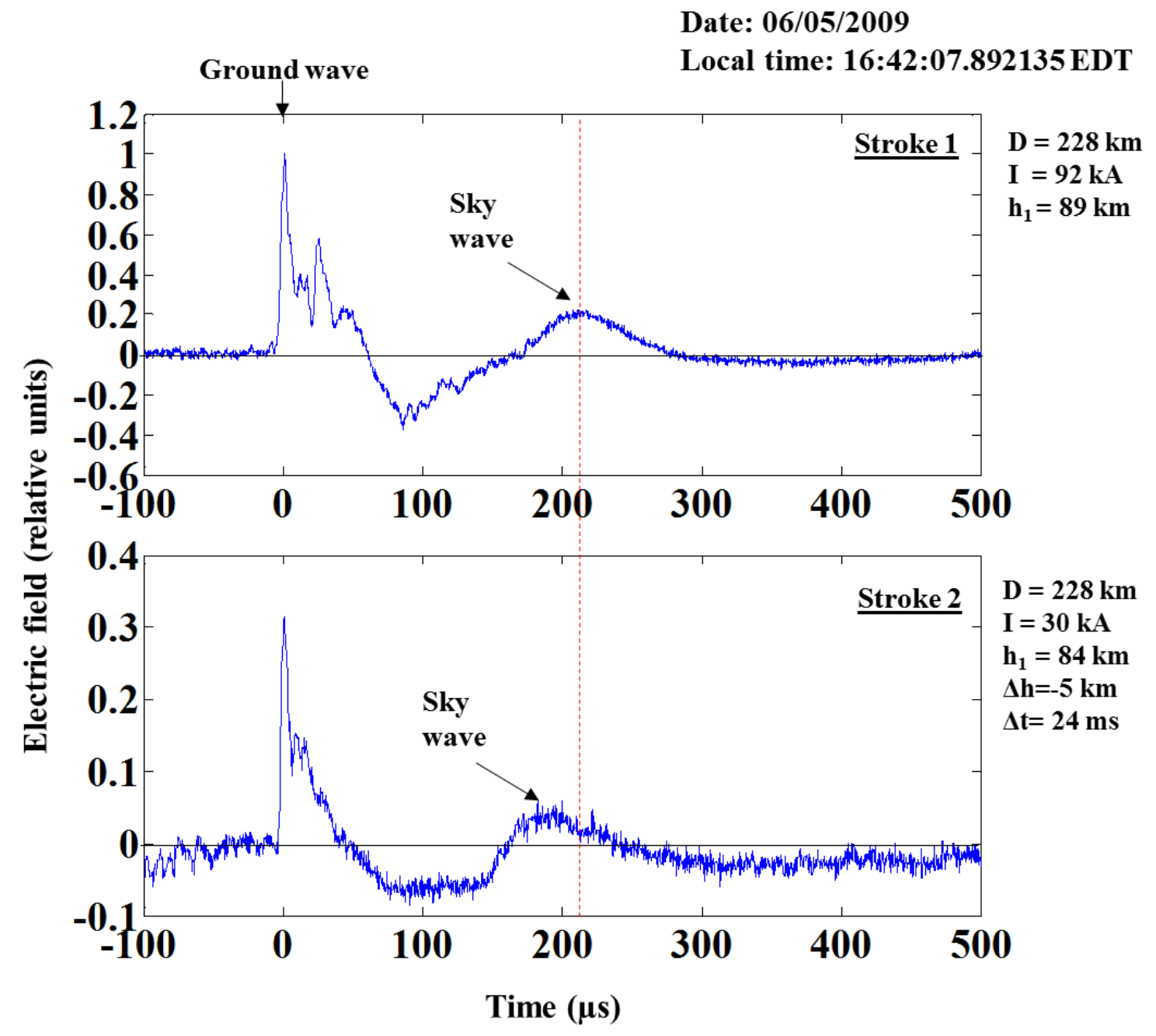

Figure 10: Two-stroke daytime flash that occurred at a distance of $228 \mathrm{~km}$ at 16:42:07.892135 EDT (first-stroke time). See also caption of Figure 11. 


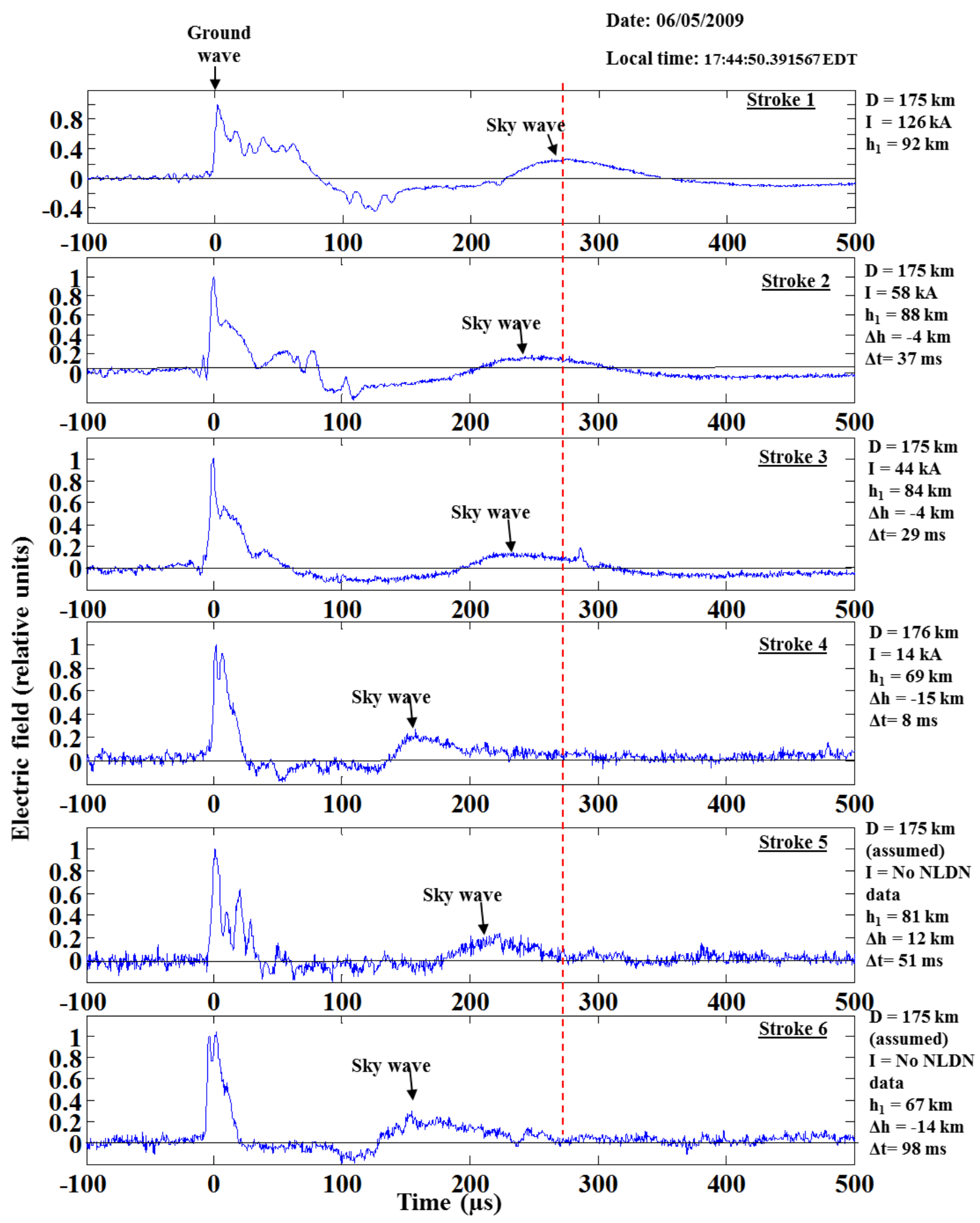

Figure 11: Vertical electric field waveforms of six negative return strokes in the same daytime flash at distances of $175-176 \mathrm{~km}$, shown on a $600 \mu \mathrm{s}$ time scale. The waveforms were recorded at 17:44:50.391567 EDT (first-stroke time). The ground wave and first skywave are marked. The vertical broken line indicates the position of the maximum of the first skywave for stroke 1. Strokes 5 and 6 were not recorded by the NLDN. Reflection heights for these strokes are calculated based on the assumption that they followed the same channel to ground as strokes 1 to 4 . I is the NLDNreported peak current and $\Delta t$ is the preceding interstroke interval. 


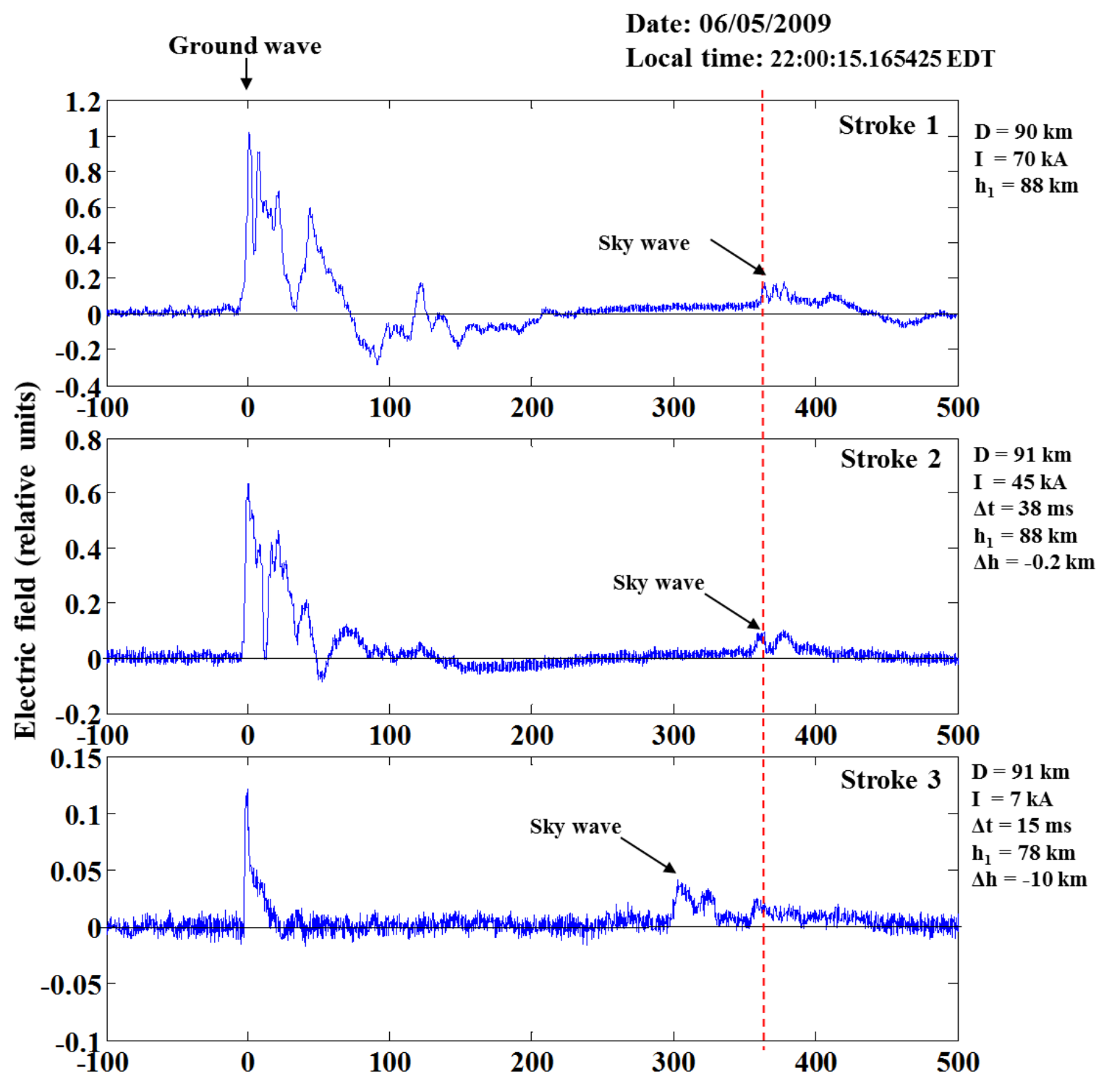

Time $(\mu s)$

Figure 12: Same as Figure 11, but for the three-stroke nighttime flash that occurred at a distance of $91 \mathrm{~km}$ at 22:00:15.165425 EDT (first-stroke time). 


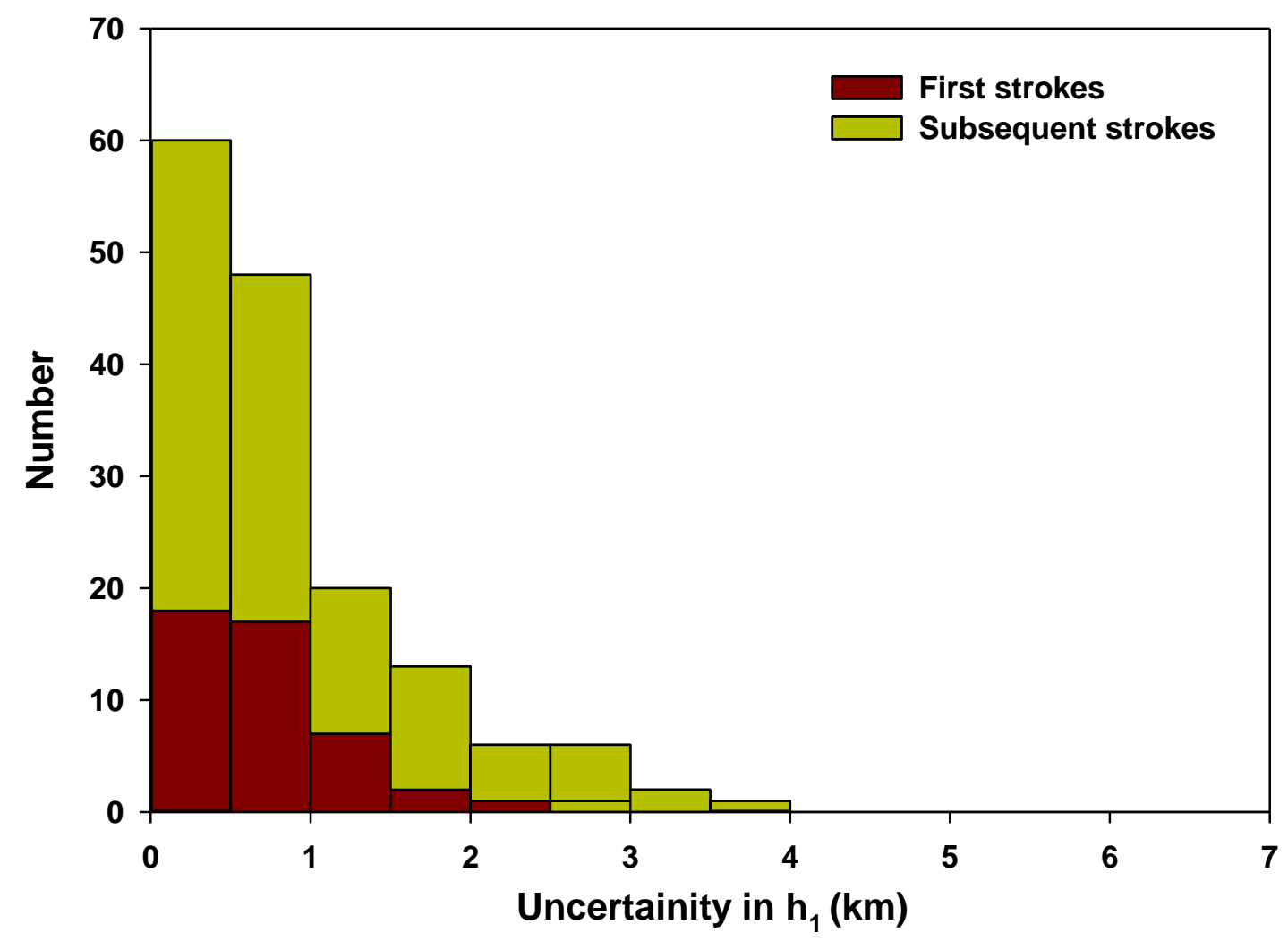

\begin{tabular}{|c|c|c|c|}
\hline $\begin{array}{c}\text { Stroke } \\
\text { type }\end{array}$ & $\begin{array}{c}\text { First } \\
\text { stroke }\end{array}$ & $\begin{array}{c}\text { Second } \\
\text { stroke }\end{array}$ & $\begin{array}{c}\text { All } \\
\text { strokes }\end{array}$ \\
\hline AM, km & $\mathbf{0 . 7}$ & $\mathbf{0 . 9}$ & $\mathbf{0 . 8}$ \\
\hline GM, km & 1.2 & 1.4 & 1.4 \\
\hline Median, km & $\mathbf{0 . 6}$ & $\mathbf{0 . 7}$ & 0.7 \\
\hline Min, km & $\mathbf{0}$ & $\mathbf{0}$ & $\mathbf{0}$ \\
\hline Max, km & $\mathbf{2 . 8}$ & $\mathbf{3 . 8}$ & 3.8 \\
\hline N & 46 & 110 & 156 \\
\hline
\end{tabular}

Figure 13: Uncertainties in reflection height $h_{1}$ due to uncertainty in measuring $t_{1}$ (only for daytime flashes containing first and one or more consecutive subsequent strokes). GM and $\mathrm{AM}$ are the geometric mean and arithmetic mean values, respectively. 


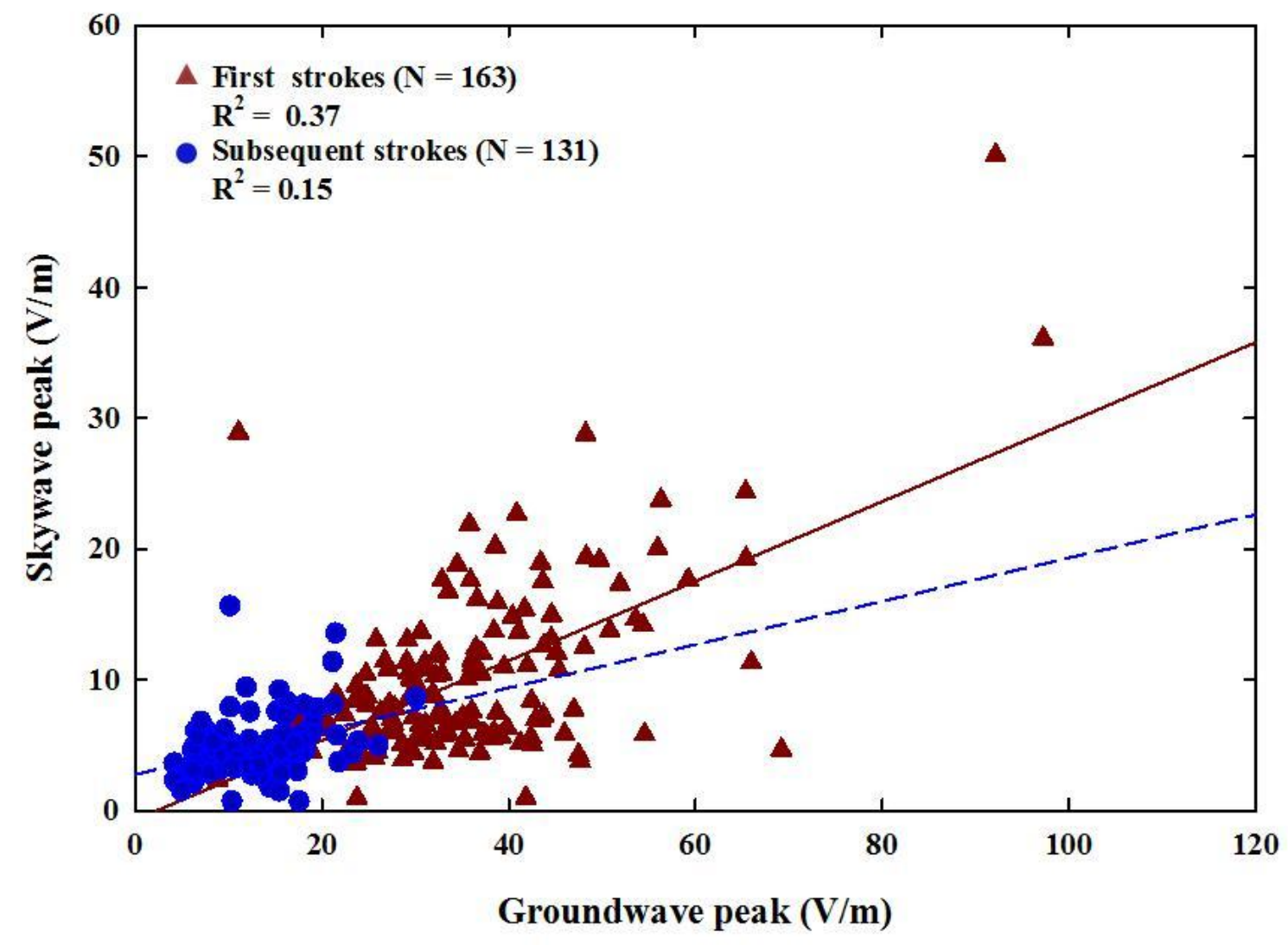

Figure 14: Scatterplot of skywave peak versus ground wave peak. Also shown are regression lines for first (solid line) and subsequent (broken line) strokes. $R^{2}$ is the determination coefficient (the square of the correlation coefficient). 


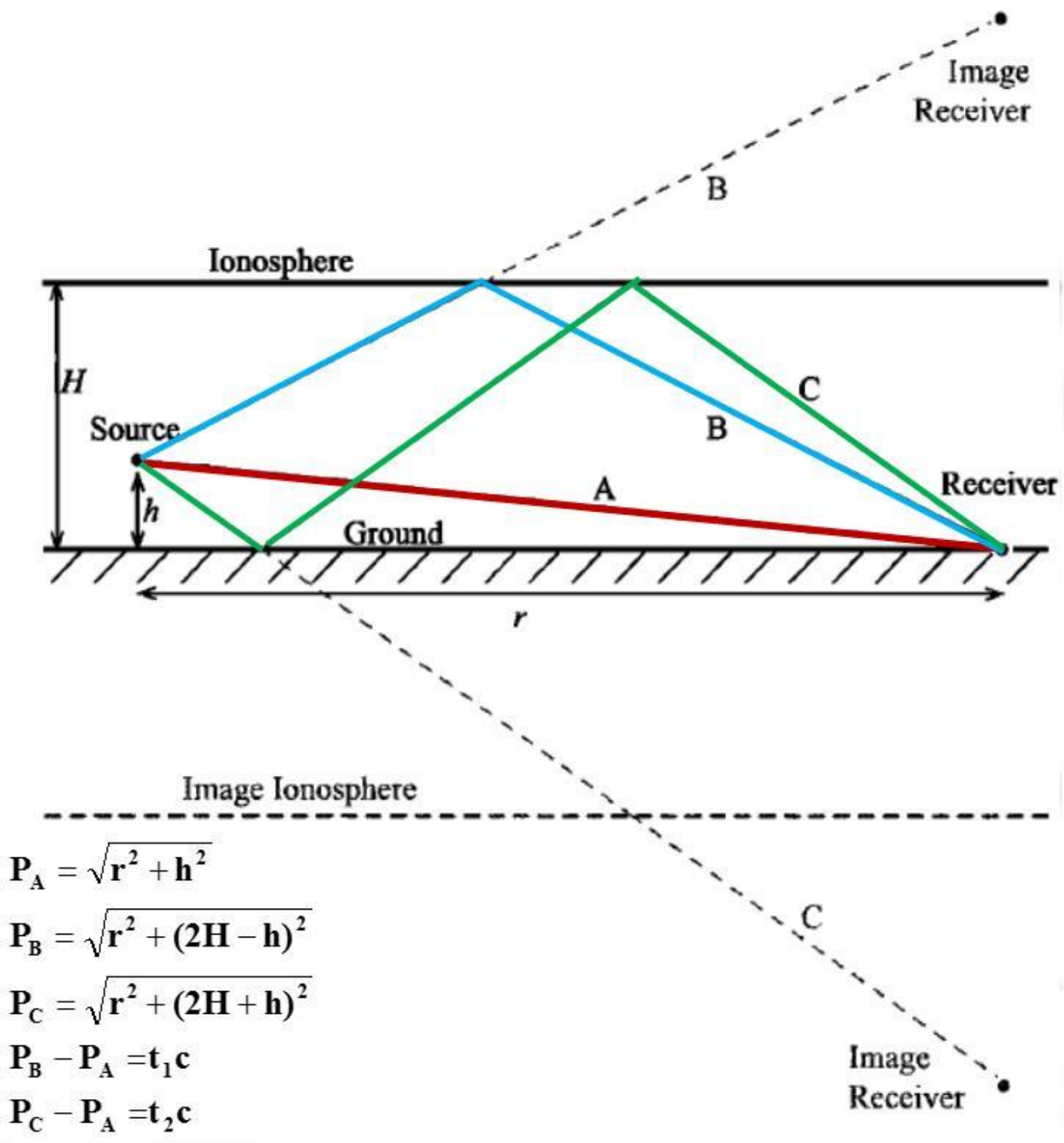

Figure 15: Geometry for calculating CID height (h) and ionospheric reflection height $(\mathrm{H})$ from the delays of ionosphere reflection (path $\mathrm{B}$ ) and ground-ionosphere reflection (path C) relative to the direct wave (path A). $P_{A}, P_{B}$, and $P_{C}$ are the propagation distances corresponding to paths $\mathrm{A}, \mathrm{B}$, and $\mathrm{C}$, respectively. $t_{1}$ and $t_{2}$ are the delays of ionospheric reflection (Path B) and ground-ionosphere reflection (Path C), respectively, relative to the direct wave. Adapted from Smith et al. [1999]. 

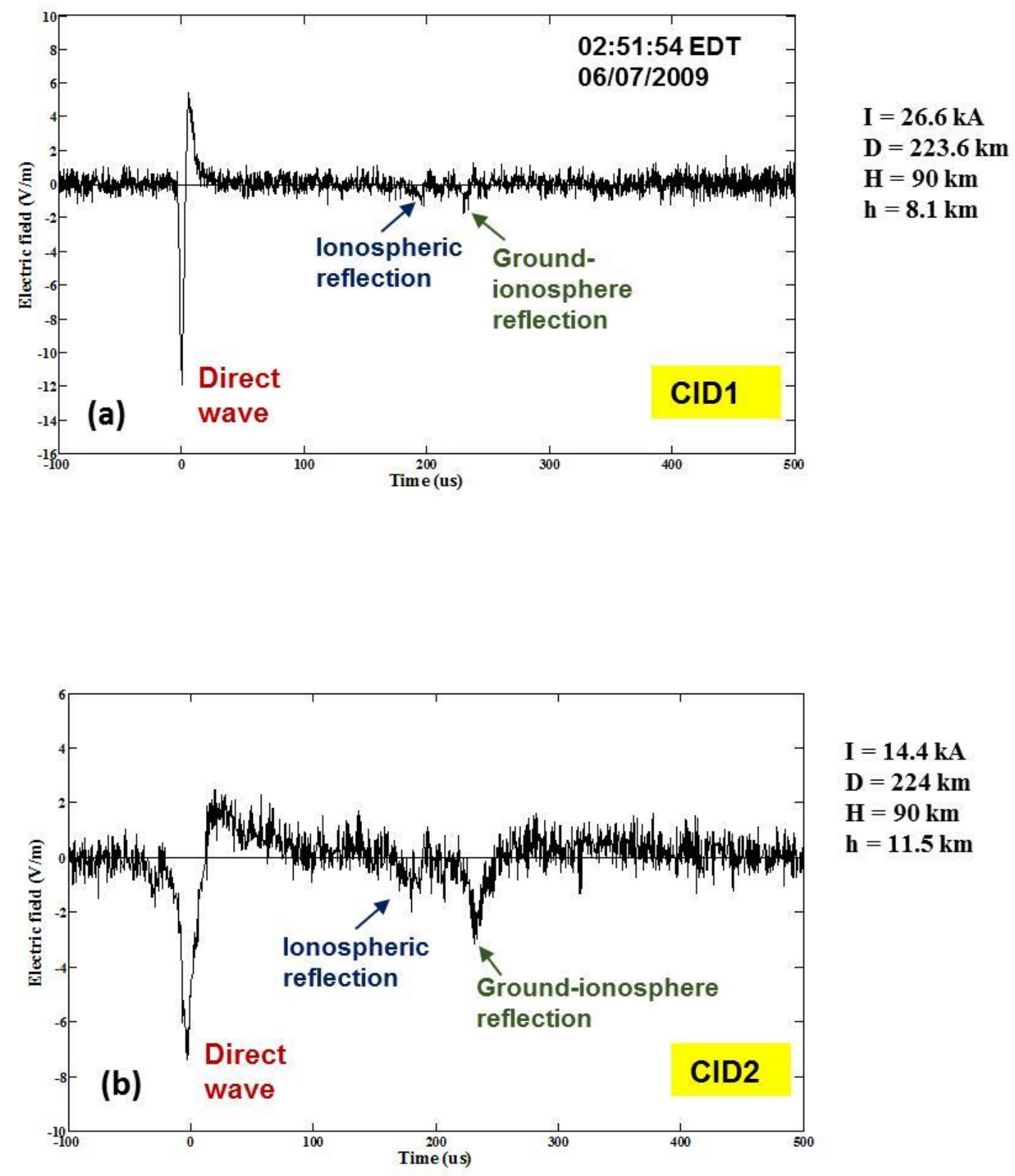

Figure 16: Electric field waveforms of (a) CID1 and (b) CID2 that occurred as a pair (138 ms apart) at night, at a distance of about $224 \mathrm{~km}$. Marked for each CID is direct wave, ionospheric reflection, and ground-ionosphere reflection. NLDN- reported peak currents, as well as estimated values of $\mathrm{h}$ and $\mathrm{H}$ are given. 
Table 1: Mean values of $t_{1}$ and $h_{1}$ for first and subsequent strokes obtained using (a) zero to-zero and (b) peak-to-peak methods to measure $t_{1}$. See also Figures 6 and 7.

(a) Zero-to-zero

(b) Peak-to-peak

\begin{tabular}{lccrc}
\hline & $t_{1}(\mu \mathrm{s})$ & $h_{1}(\mathrm{~km})$ & $t_{1}(\mu \mathrm{s})$ & $h_{1}(\mathrm{~km})$ \\
\hline First strokes $(\mathrm{n}=108)$ & 200 & 82 & 241 & 91 \\
Subsequent strokes $(\mathrm{n}=124)$ & 162 & 71 & 204 & 80 \\
\hline
\end{tabular}

The standard errors in mean values of $\mathrm{h}_{1}$ in all cases are less than $3 \%$ of the mean value.

Table 2: Daytime patterns in reflection height changes with respect to the preceding stroke for the following three cases: (a) neglecting uncertainty in $h_{1}$, (b) 2-km uncertainty, and (c) 3-km uncertainty

\begin{tabular}{|c|c|c|c|c|c|}
\hline \multicolumn{6}{|c|}{ (a) Neglecting uncertainty } \\
\hline Pattern category & $\begin{array}{l}\text { Monotonic } \\
\text { decrease }\end{array}$ & $\begin{array}{l}\text { Non-monotonic } \\
\text { variation }\end{array}$ & No change & $\begin{array}{l}\text { Monotonic } \\
\text { increase }\end{array}$ & Total \\
\hline Number & 31 & 21 & 1 & 1 & 54 \\
\hline Percentage & 57 & 39 & 2 & 2 & 100 \\
\hline \multicolumn{6}{|c|}{ (b) 2-km uncertainty } \\
\hline Pattern category & $\begin{array}{c}\text { Monotonic } \\
\text { decrease }\end{array}$ & $\begin{array}{c}\text { Non-monotonic } \\
\text { variation }\end{array}$ & No change & $\begin{array}{l}\text { Monotonic } \\
\text { increase }\end{array}$ & Total \\
\hline Number & 41 & 11 & 1 & 1 & 54 \\
\hline Percentage & 76 & 20 & 2 & 2 & 100 \\
\hline \multicolumn{6}{|c|}{ (c) 3-km uncertainty } \\
\hline Pattern category & $\begin{array}{c}\text { Monotonic } \\
\text { decrease }\end{array}$ & $\begin{array}{l}\text { Non-monotonic } \\
\text { variation }\end{array}$ & No change & $\begin{array}{l}\text { Monotonic } \\
\text { increase }\end{array}$ & Total \\
\hline Number & 45 & 7 & 1 & 1 & 54 \\
\hline Percentage & 83 & 13 & 2 & 2 & 100 \\
\hline
\end{tabular}


Table 3: Daytime patterns in reflection height changes with respect to the first stroke for the following three cases: (a) neglecting uncertainty in $h_{1}$, (b) 2-km uncertainty, and (c) 3-km uncertainty

\begin{tabular}{|c|c|c|c|c|c|}
\hline \multicolumn{6}{|c|}{ (a) Neglecting uncertainty } \\
\hline Pattern category & $\begin{array}{c}\text { Monotonic } \\
\text { decrease }\end{array}$ & $\begin{array}{l}\text { Non-monotonic } \\
\text { variation }\end{array}$ & No change & $\begin{array}{c}\text { Monotonic } \\
\text { increase }\end{array}$ & Total \\
\hline Number & 49 & 3 & 1 & 1 & 54 \\
\hline Percentage & 91 & 6 & 2 & 2 & 100 \\
\hline \multicolumn{6}{|c|}{ (b) 2-km uncertainty } \\
\hline Pattern ca & $\begin{array}{c}\text { Monotonic } \\
\text { decrease }\end{array}$ & $\begin{array}{l}\text { Non-monotonic } \\
\text { variation }\end{array}$ & No change & $\begin{array}{l}\text { Monotonic } \\
\text { increase }\end{array}$ & Total \\
\hline Number & 50 & 2 & 1 & 1 & 54 \\
\hline Percentage & 93 & 4 & 2 & 2 & 100 \\
\hline \multicolumn{6}{|c|}{ (c) 3-km uncertainty } \\
\hline Pattern c & $\begin{array}{c}\text { Monotonic } \\
\text { decrease }\end{array}$ & $\begin{array}{l}\text { Non-monotonic } \\
\text { variation }\end{array}$ & No change & $\begin{array}{c}\text { Monotonic } \\
\text { increase }\end{array}$ & Total \\
\hline Number & 51 & 1 & 1 & 1 & 54 \\
\hline Percentage & 94 & 2 & 2 & 2 & 100 \\
\hline
\end{tabular}

Table 4: Nighttime patterns in reflection height changes

\begin{tabular}{|c|c|c|c|c|c|}
\hline \multicolumn{6}{|c|}{ (a) With respect to the preceding stroke } \\
\hline Pattern category & $\begin{array}{c}\text { Monotonic } \\
\text { decrease }\end{array}$ & $\begin{array}{c}\text { Non-monotonic } \\
\text { variation }\end{array}$ & No change & $\begin{array}{c}\text { Monotonic } \\
\text { increase }\end{array}$ & Total \\
\hline Nun & 3 & 3 & 5 & 0 & 11 \\
\hline Perce & 27 & 27 & 46 & 0 & 100 \\
\hline \multicolumn{6}{|c|}{ (b) With respect to the first stroke } \\
\hline Pattern category & $\begin{array}{c}\text { Monotonic } \\
\text { decrease }\end{array}$ & $\begin{array}{l}\text { Non-monotonic } \\
\text { variation }\end{array}$ & No change & $\begin{array}{l}\text { Monotonic } \\
\text { increase }\end{array}$ & Total \\
\hline Number & 6 & 0 & 5 & 0 & 11 \\
\hline Percentage & 54 & 0 & 46 & 0 & 100 \\
\hline
\end{tabular}


Table 5: Average ionospheric reflection height vs. peak current for first strokes (estimated using the peak-to-peak method to measure $t_{1}$ )

\begin{tabular}{lcccc}
\hline Peak current range, kA & $0-50$ & $50-100$ & $100-150$ & $150-200$ \\
Mean peak current, kA & 38 & 76 & 121 & 166 \\
Mean reflection height, km & 86 & 90 & 92 & 92 \\
$\begin{array}{l}\text { Standard deviation of } \\
\text { reflection height, km }\end{array}$ & 15 & 8 & 5 & 5 \\
$\begin{array}{l}\text { Sample size } \\
\text { Standard error, km }\end{array}$ & 7 & 27 & 31 & 8 \\
\end{tabular}

Table 6: Average ionospheric reflection height vs. peak current for subsequent strokes (estimated using the peak-to-peak method to measure $t_{1}$ )

\begin{tabular}{lcccc}
\hline Peak current range, kA & \multicolumn{5}{c}{$0-20$} & $20-40$ & $40-60$ & $60-80$ \\
Mean peak current, kA & 15 & 30 & 49 & 69 \\
Mean reflection height, km & 83 & 83 & 88 & 88 \\
$\begin{array}{l}\text { Standard deviation of } \\
\text { reflection height, km }\end{array}$ & 8 & 8 & 4 & 10 \\
Sample size & 46 & 44 & 21 & 6 \\
Standard error, km & 1.2 & 1.2 & 0.8 & 4 \\
\hline
\end{tabular}

